\title{
Localized Electronic Structure of Nitrogenase FeMoco Revealed by Selenium K-Edge High Resolution X-ray Absorption Spectroscopy
}

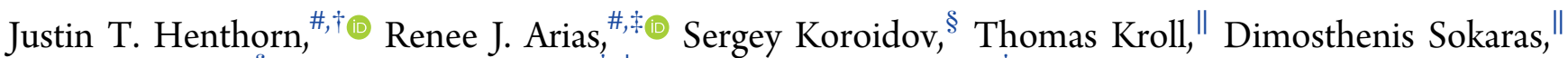

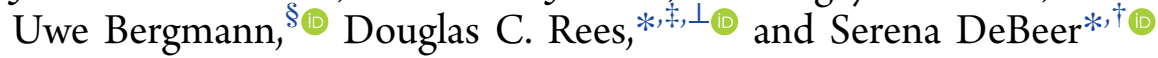

\begin{abstract}
${ }^{\dagger}$ Max Planck Institute for Chemical Energy Conversion, Stiftstr. 34-36, D-45470 Mülheim an der Ruhr, Germany
${ }^{\ddagger}$ Division of Chemistry and Chemical Engineering, California Institute of Technology, Pasadena, California 91125, United States

${ }^{\S}$ PULSE Institute, SLAC National Accelerator Laboratory, Menlo Park, California 94025, United States

"Stanford Synchrotron Radiation Lightsource, SLAC National Accelerator Laboratory, Menlo Park, California 94025, United States

${ }^{\perp}$ Howard Hughes Medical Institute, California Institute of Technology, Pasadena, California 91125, United States
\end{abstract}

Supporting Information

\begin{abstract}
The size and complexity of Mo-dependent nitrogenase, a multicomponent enzyme capable of reducing dinitrogen to ammonia, have made a detailed understanding of the FeMo cofactor (FeMoco) active site electronic structure an ongoing challenge. Selective substitution of sulfur by selenium in FeMoco affords a unique probe wherein local $\mathrm{Fe}-\mathrm{Se}$ interactions can be directly interrogated via high-energy resolution fluorescence detected X-ray absorption spectroscopic (HERFD XAS) and extended X-ray absorption fine structure (EXAFS) studies. These studies reveal a significant asymmetry in the electronic distribution of the FeMoco, suggesting a more localized electronic structure picture

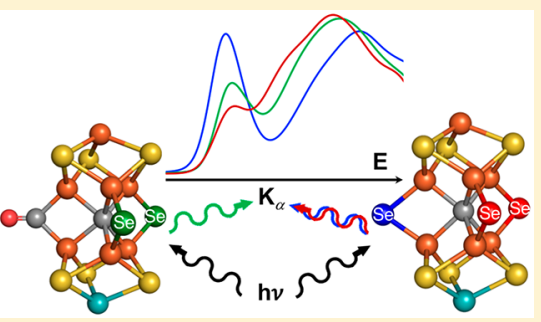
than is typically assumed for iron-sulfur clusters. Supported by experimental small molecule model data in combination with time dependent density functional theory (TDDFT) calculations, the HERFD XAS data is consistent with an assignment of $\mathrm{Fe} 2 / \mathrm{Fe} 6$ as an antiferromagnetically coupled diferric pair. HERFD XAS and EXAFS have also been applied to Se-substituted CO-inhibited MoFe protein, demonstrating the ability of these methods to reveal electronic and structural changes that occur upon substrate binding. These results emphasize the utility of Se HERFD XAS and EXAFS for selectively probing the local electronic and geometric structure of FeMoco.
\end{abstract}

\section{INTRODUCTION}

The nitrogenase family of enzymes is responsible for nearly all biological nitrogen fixation and has attracted intense mechanistic scrutiny due to its ability to reduce $\mathrm{N}_{2}$ to $\mathrm{NH}_{3}$ at ambient temperature and pressure. This is in sharp contrast to the high temperatures and pressures of the Haber-Bosch process, the industrial analogue accounting for approximately half of global nitrogen fixation. ${ }^{1,2}$ Of the known nitrogenases, molybdenum-dependent nitrogenases show by far the highest activity for $\mathrm{N}_{2}$ reduction, while vanadium-dependent nitrogenases show relatively high activity for $\mathrm{CO}$ reduction. ${ }^{3}$ Hence, nitrogenases can enable both Haber-Bosch ${ }^{4}$ and FischerTropsch $^{5}$ chemistry with varied efficiencies. Due to the ability of the enzyme to tune the reactivity of the active site to selectively and efficiently carry out these challenging chemical transformations, there is great interest in understanding the atomic-level details of the enzymatic mechanisms.

To date, a multitude of spectroscopic techniques-including electron paramagnetic resonance (EPR), ${ }^{6}$ Mössbauer, ${ }^{7}$ and Xray spectroscopy ${ }^{8-11}$ - have been used to interrogate the electronic structure of the FeMo cofactor (FeMoco, Figure 1). A major drawback for most of these techniques is their lack of spatial specificity, producing a signal averaged over the entire cluster that can be quite challenging to deconvolute in order to extract local electronic structure information. These spectroscopies may be further complicated by the presence of the Pand F-clusters, requisite components of nitrogenase under native turnover conditions, further limiting their utility in characterizing intermediates in the reaction cycle. While EPR spectroscopy has proven to be one of the more selective probes in studies of the nitrogenase active site (particularly more reduced states) through effective spin state discrimination, the technique is still generally limited by the signal average problem and the requirement of odd-integer-electron species, potentially excluding a number of intermediates in the catalytic cycle (though under ideal conditions some information can still be extracted from non-Kramers systems). ${ }^{12-14}$ In specific instances, the cluster signal average limit has been overcome through single crystal experiments, as demonstrated by the determination of the geometric orientation of the g-tensor in FeMoco. ${ }^{15}$ More recently, a spatially resolved anomalous dispersion (SpReAD) study ${ }^{16}$ on single crystals of MoFe protein revealed atomistic electronic structure information, suggesting that $\mathrm{Fe} 1, \mathrm{Fe} 3$, and $\mathrm{Fe} 7$ were fully localized $\mathrm{Fe}^{2+}$, while the remainder of the $\mathrm{Fe}$ centers in FeMoco were local

Received: July 2, 2019

Published: July 29, 2019 


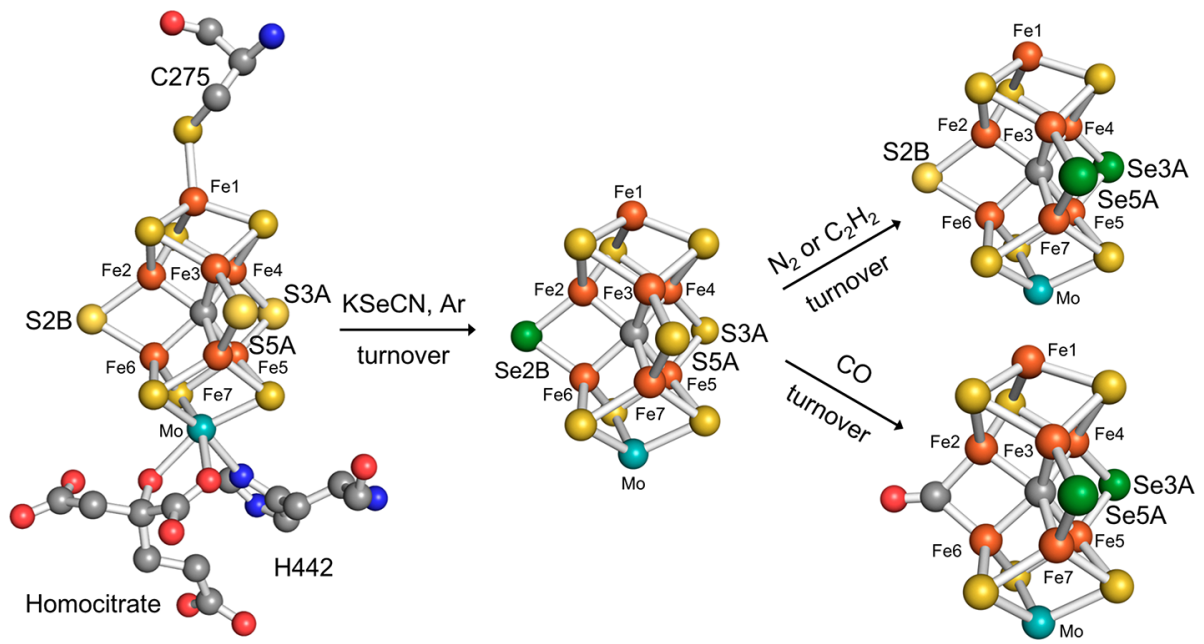

Figure 1. Summary of Se incorporation and migration reactions in FeMoco from A. vinelandii (PDB-IDs 3U7Q, 5BVG, 5BVH). Nitrogen atoms are shown in blue, oxygen atoms in red, and carbon atoms in gray.

$\mathrm{Fe}^{3+}$ (assuming the $\left[\mathrm{MoFe}_{7} \mathrm{~S}_{9} \mathrm{C}\right]^{1-}$ charge $^{17}$ for $\mathrm{FeMoco}$ ). This proposal of localized Fe oxidation states in FeMoco contrasts with the delocalization typically observed in larger (i.e. $>2 \mathrm{Fe}$ ) $\mathrm{FeS}$ clusters. ${ }^{18,19}$ Additionally, since this technique requires single crystals, it is challenging to extend beyond a select set of states. The highly localized electronic structure picture derived from the recent SpReAD study, ${ }^{16}$ together with the partially localized electronic structure calculated from recent broken symmetry QM/MM studies, ${ }^{20}$ have raised questions as to how localized or delocalized the electronic structure is in FeMoco. These questions further motivate the development of selective probes of the local electronic structure of FeMoco that are not simply limited to the resting state, but can also be extended to more reduced states and catalytic intermediates.

It was previously reported that addition of $\mathrm{KSeCN}$ to $\mathrm{MoFe}$ protein under proton-reducing turnover conditions (argon atmosphere) results in incorporation of $\mathrm{Se}$ at the bridging positions of the FeMoco cluster, ${ }^{21}$ with initial selenium substitution occurring at the $2 \mathrm{~B}$ position (Figure 1). Under turnover in the presence of nonproton substrate $\left(\mathrm{N}_{2}\right.$ or acetylene), it was observed that the Se migrates from the $2 \mathrm{~B}$ position to the $3 \mathrm{~A}$ and $5 \mathrm{~A}$ positions. Additionally, it was found that exposure of the Se-substituted cofactor to $\mathrm{CO}$ under turnover also results in migration of the Se to the $3 \mathrm{~A}$ and $5 \mathrm{~A}$ positions with $\mathrm{CO}$ bridging $\mathrm{Fe} 2$ and $\mathrm{Fe} 6$. The discovery that the belt $\mathrm{S}$ atoms of FeMoco can be substituted by Se presents a new avenue for extracting localized electronic structure information from FeMoco, as introducing an element not natively found in the nitrogenase protein generates a selective probe for X-ray spectroscopy. The demonstrated siteselectivity of Se for the belt positions (with no incorporation observed elsewhere in the protein $)^{21}$ allows selective interrogation of the six Fe's bound to the central carbide via the bridging Se atoms. By varying the extent of Se substitution, it is possible to further narrow the information content by deconvoluting the $2 \mathrm{~B}$ position from the $3 \mathrm{~A}$ and $5 \mathrm{~A}$ positions. Additionally, through reaction with $\mathrm{CO}$, it is possible to selectively probe the electronic structure of a substrate bound intermediate. Herein, we demonstrate the utility of selenium substitution in FeMoco as a selective probe of the cluster's local electronic structure.

\section{METHODS}

2.1. Protein Sample Preparations. Detailed descriptions of the preparation and analysis of the protein samples can be found in the Supporting Information. A succinct description of the four samples investigated can be found below.

$A v 1 S e_{10}$ and $A v 1 S e_{h i}$. Se-incorporated FeMoco was prepared with slight modifications to methods previously described. ${ }^{21,22}$ Two different Se-substituted FeMoco samples were prepared that differed in the concentration of $\mathrm{KSeCN}$ used. Av1Se $\mathrm{e}_{\mathrm{o}}$ was prepared from a $250 \mathrm{uM} \mathrm{KSeCN}$ solution, while $\mathrm{Av}_{1} \mathrm{Se}_{\mathrm{hi}}$ was prepared from a $10 \mathrm{mM}$ $\mathrm{KSeCN}$ solution.

Av1SeCO. CO-inhibition of Av1-Se was achieved with methods previously described with some adjustments. ${ }^{21-23} \mathrm{~A}$ sample of Sesubstituted FeMoco was prepared (using $10 \mathrm{mM} \mathrm{KSeCN}$ as described above), and after successful selenocyanate-inhibition (as determined by acetylene reduction assays), the system was placed under an atmosphere of $\mathrm{CO}$ and allowed to react for $20 \mathrm{~min}$. All further manipulation and purification steps were performed under an atmosphere of $\mathrm{CO}$ and using $\mathrm{CO}$-saturated solutions.

$A v 1 S e_{\text {reac }}$ The protein was substituted with Se $(10 \mathrm{mM} \mathrm{KSeCN})$, inhibited with $\mathrm{CO}$ as described above, and then reactivated from $\mathrm{CO}$. Reactivation from $\mathrm{CO}$ consisted of bubbling a fresh reaction mixture containing all activity components with Ar to replace excess CO. Reactivation from $\mathrm{CO}$ of native FeMoco (no Se labeling) has previously been reported, ${ }^{23}$ with the reincorporation of $S$ at the $2 B$ position confirmed crystallographically.

Each protein sample was then divided into material for inductively coupled plasma mass spectrometric (ICP-MS), anomalous dispersion, and XAS studies (see Supporting Information for detailed analyses).

2.2. ICP-MS. Protein samples were analyzed for bulk $\mathrm{Fe}, \mathrm{Mo}$, and Se content using a quadrupole-based inductively coupled plasma-mass spectrometer (Agilent 8800 ICP-QQQ) at the Environmental Analysis Center at Caltech. Samples were analyzed in helium mode to avoid any argon-argon dimers that may form in the plasma. Calibrations were generated by comparing ion counts from selenium, molybdenum, and iron standards, all prepared in $2 \% \mathrm{HNO}_{3}$.

2.3. Anomalous Dispersion. Protein single crystal diffraction data were collected at $7110 \mathrm{eV}(1.743 \AA)$ and $12662 \mathrm{eV}(0.979 \AA)$ at the Stanford Synchrotron Radiation Lightsource (SSRL) beamline 12-2 equipped with a Dectris Pilatus $6 \mathrm{M}$ detector. Se-anomalous density maps were calculated based on the data collected at 12662 $\mathrm{eV}$, while the $\mathrm{S}$-anomalous maps were calculated based on the data collected at $7110 \mathrm{eV}$ (see Supporting Information for detailed data processing).

2.4. HERFD XAS and EXAFS Data Collection. Se K-edge HERFD XAS and EXAFS measurements were performed at beamline 6-2 located at the Stanford Synchrotron Radiation Lightsource 
facility, operated at $3 \mathrm{GeV}$ with an electron beam current of $500 \mathrm{~mA}$. Beamline 6-2 uses radiation from a 56-pole, $0.9 \mathrm{~T}$ wiggler, delivering $\sim 10^{12}$ photons $/ \mathrm{s}(12.5 \mathrm{keV})$ at the sample position in a spot of $\sim 150$ $\mu \mathrm{m} \times \sim 400 \mu \mathrm{m}$ (vertical $\times$ horizontal). A rhodium-coated silicon mirror was used to collimate the beam vertically, and a double-crystal monochromator equipped with $\mathrm{Si}(311)$ crystals was used to select the energy with a resolution $(\Delta E / E)$ of $\sim 10^{-5}$. Energy selection of the emitted X-rays was accomplished using five spherically bent $\mathrm{Si}(844)$ crystals aligned on intersecting Rowland circles. ${ }^{24} \mathrm{~A}$ helium-filled bag was placed between the sample, the analyzer crystals, and the detector to reduce attenuation of the fluorescence signal. Measurements were performed in a liquid helium flow cryostat maintained at $\sim 20 \mathrm{~K}$. Internal energy calibration was achieved by assigning the maximum of gray elemental selenium to $12659.8 \mathrm{eV}$.

2.5. HERFD XAS and EXAFS Data Processing. HERFD XAS spectra were background corrected and normalized by fitting the edge-jump to 1. Experimental spectra were fit in an energy range from 12640 to $12670 \mathrm{eV}$ as a sum of $1-3$ pseudo-Voigt functions in the pre-edge region and 3-5 pure Gaussian functions in the edge region using an iterative least-squares Matlab script. In all cases, the fits converged to pre-edge pseudo-Voigt functions with $\leq 30 \%$ Lorentzian composition. All energies and areas reported are from the corresponding fits, with pre-edge areas taken as the sum of the areas of the pre-edge functions multiplied by 100 . Edge energies are reported as the white line maxima and pre-edge energies are reported as the maximum of the sum of the pre-edge functions. Deconvolutions were performed using the Se occupancies (Table S1) derived from the anomalous dispersions experiments (see Supporting Information). Se HERFD EXAFS spectra were initially averaged in Matlab 2014b and exported for further processing within Athena. ${ }^{25}$ A second order polynomial was fit to the pre-edge region and subtracted throughout the entire EXAFS spectrum. A three-region cubic spline (with the AUTOBK function within Athena) was employed to model the background function to a minimum of $k=12.9 \AA^{-1}$ for all spectra. Fourier transforms were performed over a windowed $k$-range from 2 to $12 \AA^{-1}$.

2.6. EPR Spectroscopy. EPR spectra were recorded at the Caltech Electron Paramagnetic Resonance Facility with a Bruker EMX X-band CW-EPR spectrometer with an Oxford ESR 900 liquid helium/nitrogen flow-through cryostat. EPR spectra were recorded at $10 \mathrm{~K}$ with microwave power $2 \mathrm{~mW}$ and microwave frequency $10 \mathrm{GHz}$.

2.7. Computational Details. All geometry optimizations and TDDFT $^{26-28}$ calculations were executed using ORCA ${ }^{29}$ version 4.1. Computations were performed using the hybrid $\mathrm{TPSSh}^{30,31}$ functional with the $\mathrm{D} 3 \mathrm{BJ}^{32,33}$ dispersion correction and CPCM solvation model. The ZORA ${ }^{34,35}$ relativistic approximation was used and employed the relativistically contracted def2 Ahlrichs ${ }^{36,37}$ basis set. A triple- $\zeta$ ZORA-def2-TZVP basis set was used for all $\mathrm{Se}, \mathrm{Fe}, \mathrm{S}$, and $\mathrm{N}$ atoms, while a double- $\zeta$ def2-SVP basis set was used for all other atoms. The RIJCOSX $^{38,39}$ approximation was used to speed up Coulomb and exchange integrals. For the complexes discussed in this work, appropriate antiferromagnetic ground states were achieved starting from a "high spin" ferromagnetic solution and employing spinflip to access the broken symmetry solution.

The hybrid TDDFT calculations were performed using 100-400 roots (depending on the system) to ensure the maximum of the rising edge was calculated. S and Se spectra were plotted with applied broadenings of 1.9 and $2.0 \mathrm{eV}$ (fwhm) and shifted by constant values of +41.2 and $-77 \mathrm{eV}$, respectively. Calculated $\mathrm{S}$ and Se XAS spectra were normalized by dividing by 37 and 4.95, respectively, to reproduce pre-edge intensities observed experimentally for a $\left[\mathrm{Fe}_{2} \mathrm{~S}_{2}\right]^{n+}$ series ${ }^{40}$ and $\left[\mathrm{Et}_{4} \mathrm{~N}\right]_{2}\left[\mathrm{Fe}_{2} \mathrm{Se}_{2}(\mathrm{SPh})_{4}\right]$ and selenocystine. Sample input files for calculations can be found in the Supporting Information.

\section{RESULTS AND DISCUSSION}

3.1. S vs Se K-Edge X-ray Absorption Spectroscopies. Sulfur K-edge XAS has been extensively employed to quantify metal-ligand covalency and probe electronic effects in protein
FeS clusters. ${ }^{41-49} \mathrm{~S}$ XAS studies on nitrogenase protein have been prohibited by the high number of $S$ atoms present in FeMoco, the P-cluster, F-cluster, as well as the cysteine and methionine residues of the $\mathrm{MoFe}$ and $\mathrm{Fe}$ proteins, all of which contribute to the total signal. ${ }^{50}$ Additionally, the only existing $\mathrm{S}$ XAS study on extracted cofactor is complicated by the presence of dithionite and related decomposition products. ${ }^{51}$ While Se-substitution in iron-sulfur clusters is by no means novel, we are unaware of any previous studies wherein Se Kedge XAS was used to probe Se-substituted iron-sulfur clusters. $^{52}$ Though the information content available through Se XAS is analogous to that of $S$, in practice the achievable energy resolution in conventional Se XAS is much lower due to the significantly shorter $1 \mathrm{~s}$ core hole lifetime, ${ }^{53}$ resulting in significant line-broadening in Se K-edge spectra that can lead to a loss of chemical information.

This broadening effect can be observed in Figure 2, where the $\mathrm{S}$ and Se K-edge XAS spectra of cystine and selenocystine

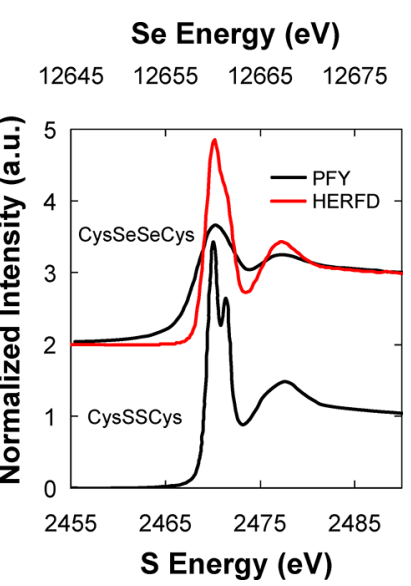

Figure 2. Comparison of $S$ and Se K-edge partial fluorescence yield (PFY) XAS spectra of cystine (bottom) and selenocystine (top, black) with high energy resolution fluorescence detected (HERFD) Se K-edge XAS spectra of selenocystine (top, red). HERFD data are from the present study. PFY data are adapted from ref 54 with permission from the Society of Biological Inorganic Chemistry (1999).

are presented. ${ }^{54}$ The S XAS spectrum of cystine reveals two well-resolved features corresponding to the $S 1$ s to $S-S^{\prime} \sigma^{*}$ and $\mathrm{S} 1 \mathrm{~s}$ to $\mathrm{S}-\mathrm{C} \sigma^{*}$ transitions at $\sim 2470 \mathrm{eV}$. In the partial fluorescence yield (PFY) Se XAS spectrum of selenocystine, the two expected features are no longer resolvable due to significant line broadening and instead a single unresolved feature is observed. This limitation can be overcome through the use of high energy resolution fluorescence detected (HERFD) XAS. ${ }^{9,11,55-57}$ By selectively measuring the $\mathrm{K}_{\alpha 1}$ fluorescence line $\left(2 \mathrm{p}_{3 / 2} \rightarrow 1 \mathrm{~s}\right)$ using high-resolution Bragg optics, $^{24}$ the effective broadening of the 1 s core hole lifetime can be suppressed. Employing this technique, the chemical information lost in the PFY spectrum of selenocystine can be recovered, as demonstrated in the HERFD Se spectrum (Figure 2, red). Using the Se HERFD technique, it is thus possible to acquire chemical information analogous to $\mathrm{S} \mathrm{K}$ edge XAS of native protein from Se-substituted FeS protein. Furthermore, selective Se substitution at different bridge positions in FeMoco allows for selective interrogation of a given bridging interaction in FeMoco, free from F- or P-cluster contributions. 


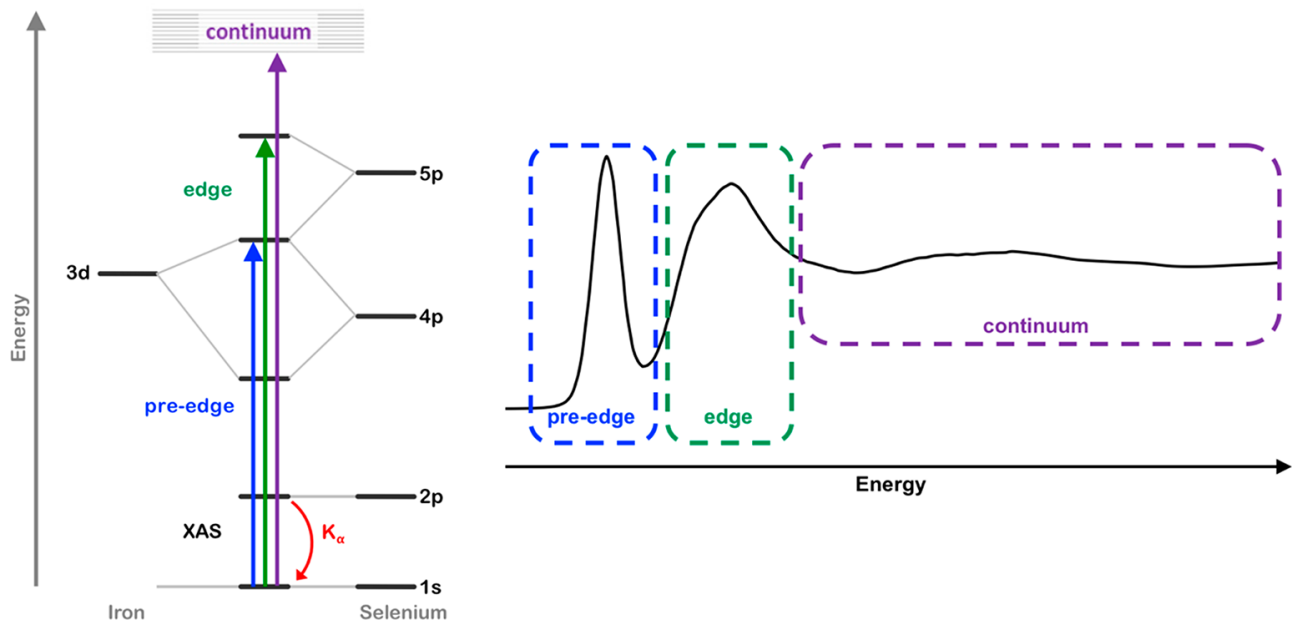

Figure 3. Simplified molecular orbital diagram (left) of Se-Fe interaction showing electronic transitions accessed in Se K-edge XAS (blue, green, and purple), as well as the $\mathrm{K}_{\alpha}$ fluorescence measured as part of the HERFD technique (red), and corresponding regions of Se K-edge XAS spectrum (right).
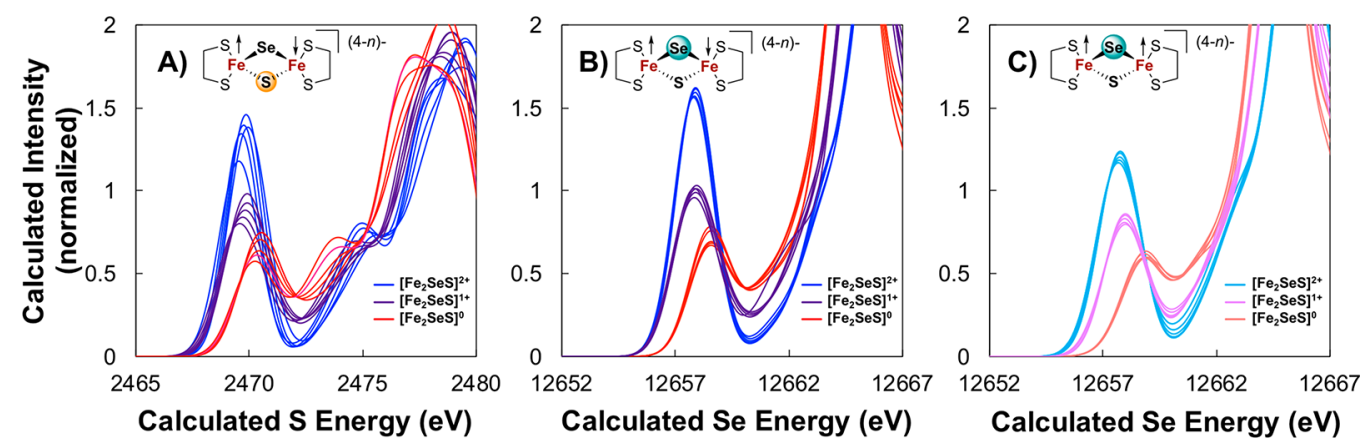

Figure 4. TDDFT calculated S XAS spectra (A) and corresponding Se XAS spectra (B) of a fictitious antiferromagnetically coupled $\left[\mathrm{Fe}_{2} \mathrm{SeS}^{n+}\right.$ series $(n=2,1,0)$ as a function of the $\mathrm{Fe}-\mathrm{Se}-\mathrm{Fe}$ angle (from $70^{\circ}$ to $90^{\circ}$ in intervals of $5^{\circ}$ ). Se XAS spectra (C) of the analogous ferromagnetically coupled $\left[\mathrm{Fe}_{2} \mathrm{SeS}\right]^{n+}$ series as a function of the $\mathrm{Fe}-\mathrm{Se}-\mathrm{Fe}$ angle (from $70^{\circ}$ to $90^{\circ}$ in intervals of $5^{\circ}$ ). Relative coupling is indicated by arrows over the $\mathrm{Fe}$ centers. Relevant quantitative data from these calculations are included in Table 1.

Table 1. Calculated and Experimental S and Se XAS Pre-edge Areas and Relative Fe 3d-Manifold Energies

\begin{tabular}{lcccccc}
\multicolumn{1}{c}{ sample } & spin-state & element & calculated pre-edge area $($ a.u. $)$ & calculated $\mid \delta_{\mathrm{d}} \mathrm{I}(\mathrm{eV})$ & experimental pre-edge area (a.u.) & experimental $\left|\delta_{\mathrm{d}}\right|(\mathrm{eV})$ \\
{$\left[\mathrm{Fe}_{2} \mathrm{SeS}\left(\mathrm{S}_{2} \mathrm{C}_{2} \mathrm{H}_{4}\right)_{2}\right]^{2-}$} & 0 & $\mathrm{~S}$ & $280 \pm 15^{a}$ & $9.50 \pm 0.20$ & - & - \\
{$\left[\mathrm{Fe}_{2} \mathrm{SeS}\left(\mathrm{S}_{2} \mathrm{C}_{2} \mathrm{H}_{4}\right)_{2}\right]^{3-}$} & $1 / 2$ & $\mathrm{~S}$ & $230 \pm 10$ & $9.05 \pm 0.20$ & - & - \\
{$\left[\mathrm{Fe}_{2} \mathrm{SeS}\left(\mathrm{S}_{2} \mathrm{C}_{2} \mathrm{H}_{4}\right)_{2}\right]^{4-}$} & 0 & $\mathrm{~S}$ & $140 \pm 15$ & $7.65 \pm 0.55$ & - & - \\
{$\left[\mathrm{Fe}_{2} \mathrm{~S}_{2}\right]^{2+b}$} & 0 & $\mathrm{~S}$ & 350 & 8.90 & 350 & 7.25 \\
{$\left[\mathrm{Fe}_{2} \mathrm{~S}_{2}\right]^{+b}$} & $1 / 2$ & $\mathrm{~S}$ & 265 & 8.70 & 260 & 6.68 \\
{$\left[\mathrm{Fe}_{2} \mathrm{~S}_{2}\right]^{0 b}$} & 0 & $\mathrm{~S}$ & 170 & 6.70 & 180 & - \\
{$\left[\mathrm{Fe}_{2} \mathrm{SeS}\left(\mathrm{S}_{2} \mathrm{C}_{2} \mathrm{H}_{4}\right)_{2}\right]^{2-}$} & 0 & $\mathrm{Se}$ & $350 \pm 5$ & $8.00 \pm 0.05$ & - & - \\
{$\left[\mathrm{Fe}_{2} \mathrm{SeS}\left(\mathrm{S}_{2} \mathrm{C}_{2} \mathrm{H}_{4}\right)_{2}\right]^{3-}$} & $1 / 2$ & $\mathrm{Se}$ & $275 \pm 5$ & $7.45 \pm 0.05$ & - & - \\
{$\left[\mathrm{Fe}_{2} \mathrm{SeS}\left(\mathrm{S}_{2} \mathrm{C}_{2} \mathrm{H}_{4}\right)_{2}\right]^{4-}$} & 0 & $\mathrm{Se}$ & $150 \pm 10$ & $6.40 \pm 0.05$ & - & - \\
{$\left[\mathrm{Fe}_{2} \mathrm{SeS}\left(\mathrm{S}_{2} \mathrm{C}_{2} \mathrm{H}_{4}\right)_{2}\right]^{2-}$} & 5 & $\mathrm{Se}$ & $285 \pm 5$ & $7.95 \pm 0.10$ & - & - \\
{$\left[\mathrm{Fe}_{2} \mathrm{SeS}\left(\mathrm{S}_{2} \mathrm{C}_{2} \mathrm{H}_{4}\right)_{2}\right]^{3-}$} & $9 / 2$ & $\mathrm{Se}$ & $195 \pm 5$ & $7.10 \pm 0.05$ & - & - \\
{$\left[\mathrm{Fe}_{2} \mathrm{SeS}\left(\mathrm{S}_{2} \mathrm{C}_{2} \mathrm{H}_{4}\right)_{2}\right]^{4-}$} & 4 & $\mathrm{Se}$ & $110 \pm 5$ & $6.15 \pm 0.05$ & - & - \\
{$\left[\mathrm{Fe}_{2} \mathrm{Se}(\mathrm{SPh})_{4}\right]^{2-}$} & 0 & $\mathrm{Se}$ & 375 & 8.10 & - & - \\
$\mathrm{Secystine}$ & 0 & $\mathrm{Se}$ & 805 & - & 385 & -
\end{tabular}

${ }^{a}$ Reported values are the mean \pm standard deviation of the 5 geometries calculated $\left(\mathrm{Fe}-\mathrm{Se}-\mathrm{Fe}\right.$ angle from 70 to $\left.90^{\circ}\right) .{ }^{b}$ Spectra originally from ref 40; data derived from fittings of experimental spectra and calculations are from present study (Figure S3).

3.2. Se K-Edge HERFD XAS. The Se HERFD XAS spectra presented in this study can be divided into two main regions: (1) the pre-edge $(\sim 12655-12659 \mathrm{eV})$ and (2) the edge $(\sim 12662-12665 \mathrm{eV})$. Pre-edge features arise primarily from a Se $1 \mathrm{~s}$ to $4 \mathrm{p}$ dipole-allowed transition that results from bonding/antibonding interactions of the Se photoabsorber, while the edge arises primarily from the dipole-allowed Se 1s to $5 \mathrm{p}$ transition and reflects the effective nuclear charge of the Se (Figure 3). Beyond the edge, the electron is excited into the continuum where it approximates a free photoelectron and can interact with electrons of neighboring atoms. The postedge region, often referred to as the extended X-ray absorption fine 
structure (EXAFS) region, can be used to obtain structural information about the photoabsorber. The studies presented herein will focus on the pre-edge and edge regions, collectively referred to as the HERFD XAS.

In the context of a $\mathrm{Se}-\mathrm{Fe}$ interaction, as the formal oxidation state of the bound $\mathrm{Fe}$ atom increases from $\mathrm{Fe}^{2+}$ to $\mathrm{Fe}^{3+}$, the corresponding Se XAS pre-edge feature is anticipated to increase in intensity (as additional holes are generated in the $\mathrm{Fe} 3 \mathrm{~d}$-manifold and the $\mathrm{Se}-\mathrm{Fe}$ interaction becomes more covalent leading to greater orbital overlap), and the edge is anticipated to shift to higher energy (as the effective nuclear charge of Se is increased). The energy of the pre-edge is not as easily predicted a priori, as an increase in the oxidation state of Fe will result in stabilization of both the Fe $3 \mathrm{~d}$ orbitals and the Se 1s orbital, shifting both the donor and acceptor orbitals lower in energy. However, if the edge energy is used to estimate the continuum, the difference in energy between the edge and pre-edge approximates the relative energy of the $\mathrm{Fe}$ $3 \mathrm{~d}$-manifold. This difference, which we will refer to as $\left|\delta_{\mathrm{d}}\right|$ (and define as $\left|\delta_{\mathrm{d}}\right|=$ |pre-edge energy - edge energy $\mid$ ), is expected to increase with increasing $\mathrm{Fe}$ oxidation state. These qualitative trends anticipated for Se HERFD XAS have been quantitatively observed at the $\mathrm{S}$ K-edge in a synthetic $\left[\mathrm{Fe}_{2} \mathrm{~S}_{2}\right]^{n}(n=2+$, $1+, 0$ ) redox series (Figures $\mathrm{S} 3-\mathrm{S} 4),{ }^{40}$ as well as other $\mathrm{Cl}$ and $\mathrm{S}$ K-edge XAS studies ${ }^{47}$ on synthetic monometallic and dimeric Fe complexes (Figures S5-S7).

These anticipated trends are further supported by timedependent density functional theory (TDDFT) calculations on a fictitious $\left[\mathrm{Fe}_{2} \mathrm{SeS}\right]^{n+}(n=0,+1,+2)$ series in which analogous $S$ (Figure 4A) and Se K-edge (Figure 4B) XAS spectra are calculated within a single complex. In Figure $4 \mathrm{~B}$ and Table 1, it can be clearly seen that the Se XAS spectra are sensitive to the oxidation state of the bound $\mathrm{Fe}^{\prime}$, demonstrating well-separated pre-edge and rising edge features dependent on the oxidation state of the dimer. These calculations indicate that $\mathrm{Se}$ is less sensitive to geometric changes compared to $S$ (each line in Figure 4 corresponds to a distinct geometry optimization in which the $\mathrm{Fe}-\mathrm{Se}-\mathrm{Fe}$ angle was fixed, ranging from 70 to $90^{\circ}$, while all other parameters are relaxed), suggesting that electronic rather than geometric effects dominate in Se XAS. This is intuitively consistent, as the larger Se would require a greater geometric distortion to similarly perturb the orbital interaction with Fe relative to the smaller S. In addition, the spectra also appear sensitive to the relative coupling between the bound $\mathrm{Fe}$ centers (Figure 4C), with antiferromagnetic coupling resulting in greater pre-edge intensity than the corresponding ferromagnetically coupled system. These results suggest that under the localized limit it may be possible to assign the coupling interaction between bridged $\mathrm{Fe}$ centers, absent any significant perturbative interactions (see section 3.7).

Finally, experimental data (Figure 5 and Table 1) on an antiferromagnetically coupled dimer complex $\left[\mathrm{Et}_{4} \mathrm{~N}\right]_{2}\left[\mathrm{Fe}_{2} \mathrm{Se}_{2}(\mathrm{SPh})_{4}\right]$ further supports these trends and the direct analogy between Se and $S$ XAS. The Se HERFD XAS spectrum of $\left[\mathrm{Et}_{4} \mathrm{~N}\right]_{2}\left[\mathrm{Fe}_{2} \mathrm{Se}_{2}(\mathrm{SPh})_{4}\right]$ reveals an intense preedge feature (area $=385$ ) consistent with the previously reported diferric $\left[\mathrm{Fe}_{2} \mathrm{~S}_{2}\right]^{2+}$ complex (S XAS pre-edge area = $350)$ as well as the TDDFT calculations of our fictitious $\left[\mathrm{Fe}_{2} \mathrm{SeS}\right]^{2+}$ complex (Se XAS pre-edge area $350 \pm 5$ ). On the basis of these analyses, the Se K-edge pre-edge intensity and $\left|\delta_{\mathrm{d}}\right|$ will be used to evaluate the nature of the $\mathrm{Se}-\mathrm{Fe}$ interaction and thus reveal local Fe electronic structure information.

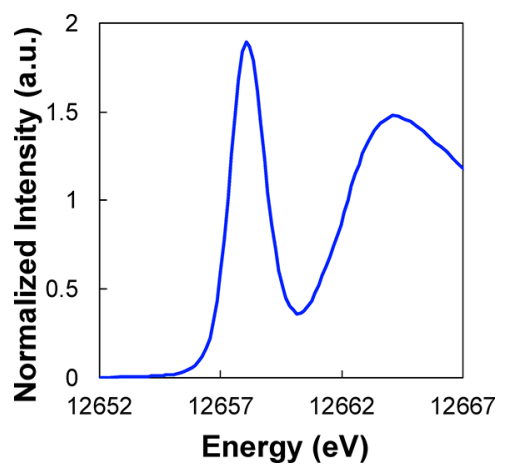

Figure 5. Experimental Se HERFD XAS spectrum of $\left[\mathrm{Et}_{4} \mathrm{~N}\right]_{2}\left[\mathrm{Fe}_{2} \mathrm{Se}_{2}(\mathrm{SPh})_{4}\right]$.

3.3. Se Incorporation in FeMoco Samples. Four different protein samples were prepared for the Se HERFD XAS studies with varied Se incorporation in the FeMoco cluster (see Supporting Information for detailed preparations): three samples of Se-incorporated FeMoco, Av1Se $e_{l o}, A_{1} 1 e_{h i}$, and $A v 1 S e_{\text {reac }}$ (with the labeling corresponding to how the samples were prepared: low concentration of $\mathrm{KSeCN}$, high concentration of $\mathrm{KSeCN}$, and reactivation after $\mathrm{CO}$-inhibition) and one CO-inhibited Se-incorporated FeMoco sample, Av1SeCO. Each of the four samples were then divided into material for anomalous dispersion, mass spectrometric, and XAS analysis. The Se incorporations, as determined by anomalous dispersion studies (Table S1), indicate that for all four samples the difference in Se occupancy between the 3A and $5 \mathrm{~A}$ positions was found to be $\leq 5 \%$, precluding any meaningful deconvolution of these two positions. Hence herein, 3A and 5A will be treated and discussed together as $3 \mathrm{~A} / 5 \mathrm{~A}$. Additionally, the anomalous dispersion data indicate $A v 1 S e_{l o}$ and $A v 1 S e_{h i}$ exhibit similar Se distributions that are majority $2 \mathrm{~B}, \mathrm{Av} 1 \mathrm{Se}_{\text {reac }}$ is more evenly distributed between $2 \mathrm{~B}: 3 \mathrm{~A} / 5 \mathrm{~A}$, and $\mathrm{Av} 1 \mathrm{SeCO}$ is majority $3 \mathrm{~A} / 5 \mathrm{~A}$.

Se incorporation in the protein samples was also quantified by inductively coupled plasma mass spectrometric (ICP-MS) studies in an effort to correlate the single crystal occupancies to the bulk sample (Table S1). Overall, the two measurements were either consistent within error or revealed lower Se:FeMoco ratios in the bulk than was found in the anomalous dispersion experiment of the single crystals. This discrepancy is attributed to the variation observed in $\mathrm{f}^{\prime \prime}$ at $12662 \mathrm{eV}$ (see Supporting Information), which can affect the absolute Se occupancy values, but will have minimal effect on the relative $2 \mathrm{~B}: 3 \mathrm{~A} / 5 \mathrm{~A}$ ratios. We conclude from these studies that samples contain negligible Se outside of the crystallographically observed FeMoco incorporation, and thus the Se HERFD XAS measurements are selectively probing the FeMoco core.

Additionally, EPR spectroscopy was employed to assess the relative perturbation of the Se substitution on the overall electronic structure of the FeMoco, as it has been previously observed that complete Se substitution in $\left[\mathrm{Fe}_{4} \mathrm{~S}_{4}\right]^{+}$cubanes can result in stabilization of alternate spin ground states $(S>1 / 2)$. 58,59 The EPR spectrum of Se-substituted FeMoco (Figure S2) reveals a broadened $S=3 / 2$ signal qualitatively similar to native FeMoco (ref 22), suggesting minimal perturbation of the FeMoco electronic structure upon Se substitution. The lack of other observable spin states by EPR, coupled with the previous finding that Se-substituted FeMoco demonstrates similar acetylene and $\mathrm{N}_{2}$ reduction activity compared to native 
protein, ${ }^{21}$ suggests Se to be a relatively innocent probe of the FeMoco electronic structure. Additionally, the EPR spectrum of CO-inhibited Se-substituted FeMoco confirms the nearcomplete loss of the $S=3 / 2$ resting state signal (consistent with the low occupancy of $\mathrm{Se} 2 \mathrm{~B}$ as determined by the anomalous dispersion experiments) and reveals a new $S=1 / 2$ signal consistent with the lo- $\mathrm{CO}$ species previously identified in the literature. ${ }^{60}$

3.4. FeMoco Se HERFD XAS. The K-edge Se HERFD XAS spectra for the four protein samples examined in this study are shown in Figure 6 and the relevant quantitative

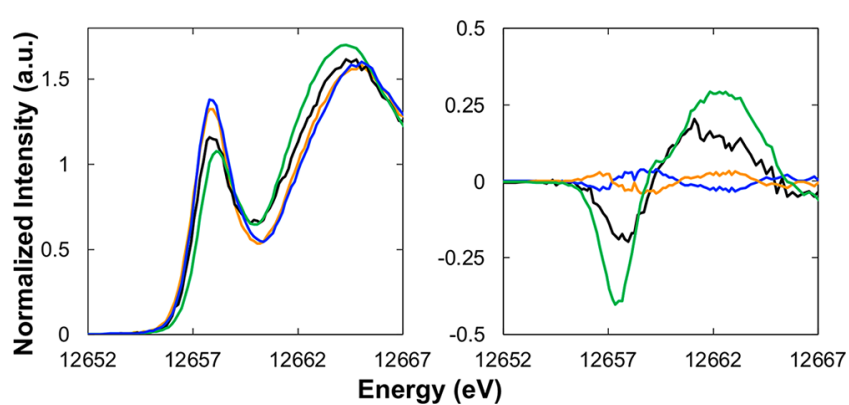

Figure 6. Experimental Se HERFD XAS (left) and corresponding difference spectra (right) of $\mathrm{AvlSe}_{\mathrm{lo}}$ (blue), Av1Se $\mathrm{h}_{\mathrm{hi}}$ (orange), $\mathrm{AvlSe}_{\text {reac }}$ (black), and Av1SeCO (green). The difference spectra are

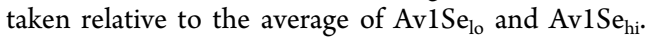

metrics are presented in Table 2. Comparing first the non-CO samples (Av1Se $e_{l o}, A v 1 S e_{h i}$, and Av1Se $e_{\text {reac }}$ ), it is immediately apparent that the spectra vary depending on the Se2B:Se3A/ $5 \mathrm{~A}$ ratios. The spectra of $A v 1 S e_{l o}$ and $A v 1 S e_{h i}$ (blue and orange, Figure 6) most closely overlap, consistent with the more similar Se occupancies observed in the two samples as determined from the anomalous dispersion studies, while the spectrum of Av1Se $e_{\text {reac }}$ (black, Figure 6) exhibits a less intense pre-edge feature and an edge shifted to lower energy. These experimental results thus suggest that the $\mathrm{Se} 2 \mathrm{~B}$ and $\mathrm{Se} 3 \mathrm{~A} / 5 \mathrm{~A}$ positions in FeMoco are electronically distinct. This becomes more obvious when looking at the difference spectra (Figure 6, right). As $\mathrm{Av}_{\mathrm{Se}} \mathrm{e}_{\mathrm{lo}}$ and $\mathrm{Av1Se} \mathrm{h}_{\mathrm{hi}}$ demonstrate near-identical relative $\mathrm{Se}$ occupancies as determined by anomalous dispersion, the difference spectra are given relative to the average of $A v 1 S e_{l o}$ and Av1Se $e_{\text {hi }}$. Thus, the difference spectra for $A v 1 \mathrm{Se}_{\mathrm{lo}}$ and $\mathrm{AvlSe} \mathrm{hi}_{\mathrm{hi}}$ are mirror images and represent an estimate of the absolute error over both the anomalous dispersion and Se HERFD XAS measurements, while the difference spectra for $A v 1 S e_{\text {reac }}$ and $\mathrm{Av} 1 \mathrm{SeCO}$ reveal the significant electronic changes observed by increasing the relative amount of $\mathrm{Se} 3 \mathrm{~A} / 5 \mathrm{~A}$ in these samples compared to $\mathrm{Av}_{\mathrm{S}} \mathrm{e}_{\mathrm{lo} / \mathrm{hi}}$.

From the HERFD XAS of these three samples (Av1Se $e_{10}$, $A v 1 S e_{h i}$, and $A v 1 S e_{\text {reac }}$ ), we can observe that as the fraction of $\mathrm{Se} 2 \mathrm{~B}$ decreases going from $\mathrm{Av} 1 \mathrm{Se} \mathrm{e}_{\mathrm{lo}}$ and $\mathrm{Av} 1 \mathrm{Se} \mathrm{e}_{\mathrm{hi}}$ to Av1Se $\mathrm{e}_{\text {reac }}$ ( 0.74 to 0.53 ), the pre-edge intensity similarly decreases, with $\mathrm{AvlSe}_{\mathrm{lo}} \geq \mathrm{Av1Se}_{\mathrm{hi}}>\mathrm{Av} 1 \mathrm{Se}_{\mathrm{reac}}$. Correspondingly, as the fraction of $\mathrm{Se} 2 \mathrm{~B}$ decreases from $\mathrm{Av}_{\mathrm{SSe}}$ and $\mathrm{Av} 1 \mathrm{Se} \mathrm{h}_{\mathrm{hi}}$ to $A v 1 S e_{\text {reac }},\left|\delta_{\mathrm{d}}\right|$ also decreases, with $\mathrm{Av}_{\mathrm{S}} \mathrm{e}_{\mathrm{hi}} \geq \mathrm{Av}_{\mathrm{Se}} \mathrm{e}_{\mathrm{lo}}>$ Av1Se $e_{\text {reac }}$. Together these two trends suggest that Se2B engages in a more covalent interactions with $\mathrm{Fe} 2 / \mathrm{Fe} 6$ compared to the average of the $\mathrm{Se} 3 \mathrm{~A} / 5 \mathrm{~A}$ interactions with $\mathrm{Fe} 4 / \mathrm{Fe} 5 / \mathrm{Fe} 3 / \mathrm{Fe} 7$, resulting in a more intense pre-edge feature and greater stabilization of the $\mathrm{Fe} 3 \mathrm{~d}$-manifold. Comparing next Av1Se $e_{\text {reac }}$ to Av1SeCO (Figure 6, green), the two spectra exhibit similar pre-edge areas (285 vs 260$)$ and $\left|\delta_{\mathrm{d}}\right|$ values (6.33 vs 6.15), though Av1SeCO contains a significantly higher fraction of Se3A/5A contributing to the spectrum (0.88 in $\mathrm{Av} 1 \mathrm{SeCO}$ vs 0.48 in $\left.\mathrm{Av} 1 \mathrm{Se}_{\mathrm{reac}}\right)$. This observation suggests not only that the $\mathrm{Se} 2 \mathrm{~B}$ and the $\mathrm{Se} 3 \mathrm{~A} / 5 \mathrm{~A}$ are electronically distinct, but also that the $\mathrm{Se} 3 \mathrm{~A} / 5 \mathrm{~A}$ position is electronically perturbed upon $\mathrm{CO}$ binding to the cofactor.

Using the Se-occupancy populations derived from the anomalous dispersion studies, the pure $\mathrm{Se}_{2 \mathrm{~B}}$ spectrum could be deconvoluted from $\mathrm{Se}_{3 \mathrm{~A} / 5 \mathrm{~A}}$ (Figure 7, blue and red spectra).

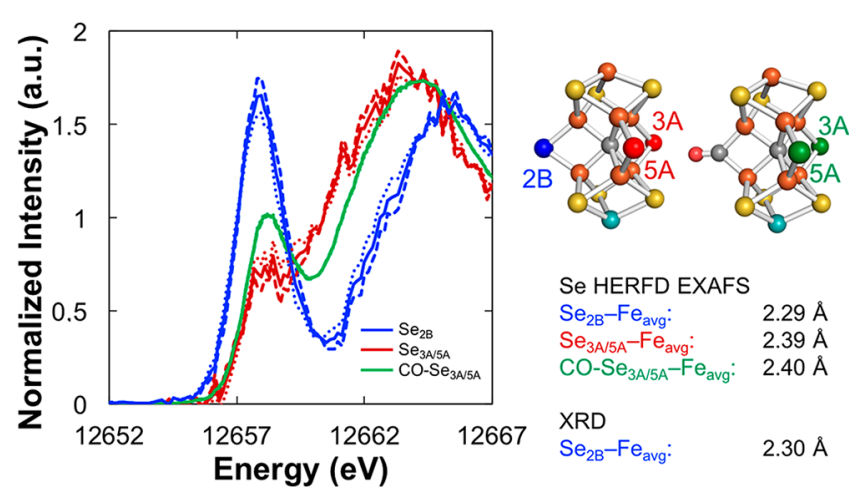

Figure 7. Deconvoluted experimental HERFD Se K-edge XAS spectra (left) of $\mathrm{Se}_{2 \mathrm{~B}}$ (blue), $\mathrm{Se}_{3 \mathrm{~A} / 5 \mathrm{~A}}$ (red), and $\mathrm{CO}-\mathrm{Se}_{3 \mathrm{~A} / 5 \mathrm{~A}}$ (green). The dashed lines are deconvolutions using $A v 1 S e_{1 o} / A v 1 S e_{\text {reac }}$ the dotted lines using $A v 1 \mathrm{Se}_{\mathrm{hi}} / \mathrm{Av} 1 \mathrm{Se} \mathrm{reac}_{\text {rec }}$ and the solid lines the average of the two. Corresponding average $\mathrm{Se}-\mathrm{Fe}$ distances extracted from $\mathrm{Se}$ HERFD EXAFS data are also presented (right).

From the three Se-incorporated MoFe samples investigated $\left(A v 1 S e_{l o}, A v 1 S e_{h i}\right.$ and $\left.A v 1 S e_{\text {reac }}\right)$, two sets of deconvolutions could be obtained which differ only by minor $(<5 \%)$

Table 2. Se HERFD XAS Edge Energies, Pre-edge Energies and Areas, and Relative Fe 3d-Manifold Energies

\begin{tabular}{|c|c|c|c|c|}
\hline \multirow[b]{2}{*}{ sample } & \multirow{2}{*}{$\frac{\text { edge }}{\text { energy }(\mathrm{eV})}$} & \multicolumn{2}{|c|}{ pre-edge } & \multirow[b]{2}{*}{$\left|\delta_{\mathrm{d}}\right|(\mathrm{eV})$} \\
\hline & & energy $(\mathrm{eV})$ & area & \\
\hline$\left[\mathrm{Et}_{4} \mathrm{~N}\right]_{2}\left[\mathrm{Fe}_{2} \mathrm{Se}_{2}(\mathrm{SPh})_{4}\right]$ & 12664.10 & 12658.05 & 370 & 6.05 \\
\hline $\mathrm{Av} \mathrm{Se}_{\mathrm{lo}}$ & 12664.80 & 12657.98 & 330 & 6.82 \\
\hline $\mathrm{Av}_{\mathrm{SSe}} \mathrm{hi}_{\mathrm{h}}$ & 12664.80 & 12657.92 & 315 & 6.88 \\
\hline $\mathrm{Av} 1 \mathrm{Se}_{\text {reac }}$ & 12664.30 & 12657.97 & 285 & 6.33 \\
\hline Av1SeCO & 12664.30 & 12658.15 & 260 & 6.15 \\
\hline $\mathrm{Se}_{2 \mathrm{~B}}$ & $12665.23 \pm 0.06$ & $12657.86 \pm 0.06$ & $385 \pm 20$ & $7.38 \pm 0.12$ \\
\hline $\mathrm{Se}_{3 \mathrm{~A} / 5 \mathrm{~A}}$ & $12663.78 \pm 0.40$ & $12658.02 \pm 0.36$ & $130 \pm 30$ & $5.76 \pm 0.04$ \\
\hline $\mathrm{CO}-\mathrm{Se}_{3 \mathrm{~A} / 5 \mathrm{~A}}$ & $12664.13 \pm 0.10$ & $12658.18 \pm 0.04$ & $245 \pm 10$ & $5.95 \pm 0.08$ \\
\hline
\end{tabular}


contributions in $3 \mathrm{~A}$ or $5 \mathrm{~A}$. These deconvolutions were performed by treating the experimental spectra as the sum of the pure $\mathrm{Se}_{2 \mathrm{~B}}$ and $\mathrm{Se}_{3 \mathrm{~A} / 5 \mathrm{~A}}$ spectra weighted by the relative $\mathrm{Se}$ populations at the $2 \mathrm{~B}$ and $3 \mathrm{~A} / 5 \mathrm{~A}$ positions. Thus, the deconvolutions can be expressed by the following two systems of equations:

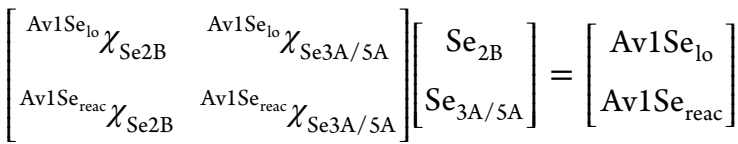

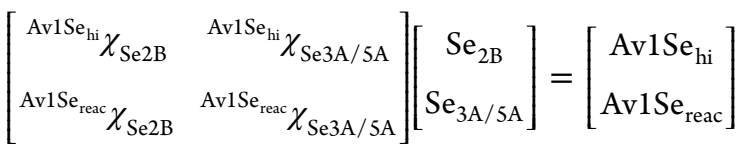

where ${ }^{A v 1 S e_{10}} \chi_{\text {Se2B }}$ corresponds to the mole fraction of Se2B in sample $A v 1 \mathrm{Se}_{\mathrm{lo}}, \mathrm{Se}_{2 \mathrm{~B}}$ is the pure spectrum of Se2B, and Av1Se is the experimental spectrum of sample Av1Se $e_{10}$. Solving these two systems of equations results in two sets of pure $\mathrm{Se}_{2 \mathrm{~B}}$ and $\mathrm{Se}_{3 \mathrm{~A} / 5 \mathrm{~A}}$ spectra, represented as dashed and dotted lines, respectively, in Figure 7, and the average given as a solid line. The two sets of deconvoluted spectra are qualitatively identical and represent an estimate of the combined error over both the Se quantification and HERFD XAS measurements. As such, the data presented in Table 2 correspond to the average of the two deconvolutions mentioned above, with the difference between the two deconvolutions reported as the error. Using the deconvoluted $\mathrm{Se}_{2 \mathrm{~B}}$ spectra, the $11 \%$ occupancy of $\mathrm{Se} 2 \mathrm{~B}$ present in $\mathrm{Av} 1 \mathrm{SeCO}$ was subtracted to afford the pure $\mathrm{Se} 3 \mathrm{~A} / 5 \mathrm{~A}$ spectrum of CO-bound FeMoco, CO-Se $3 \mathrm{~A} / 5 \mathrm{~A}$ (Figure 7 , green spectra). From these deconvolutions, the electronic differences between the $\mathrm{Se} 2 \mathrm{~B}$ and $\mathrm{Se} 3 \mathrm{~A} / 5 \mathrm{~A}$ positions, as well as the differences observed at Se3A/5A upon CO binding, can be more clearly visualized and thoroughly analyzed.

As can be seen in Table 2 and Figure 7, the deconvoluted spectra of $\mathrm{Se}_{2 \mathrm{~B}}$ and $\mathrm{Se}_{3 \mathrm{~A} / 5 \mathrm{~A}}$ are dramatically different, with $\mathrm{Se}_{2 \mathrm{~B}}$ exhibiting a very intense pre-edge feature at $12657.9 \mathrm{eV}$, while $\mathrm{Se}_{3 \mathrm{~A} / 5 \mathrm{~A}}$ exhibits a significantly less intense pre-edge only onethird the area of the $\mathrm{Se}_{2 \mathrm{~B}}$ feature $(130 \pm 30$ vs $385 \pm 20)$. This large difference in pre-edge intensity is matched by an equally large shift in the edges of the two spectra, with the $\mathrm{Se}_{3 \mathrm{~A} / 5 \mathrm{~A}}$ edge shifted $1.5 \mathrm{eV}$ to lower energy. The spectrum of $\mathrm{CO}-\mathrm{Se}_{3 \mathrm{~A} / 5 \mathrm{~A}}$ reveals a pre-edge feature intermediate in intensity between $\mathrm{Se}_{2 \mathrm{~B}}$ and $\mathrm{Se}_{3 \mathrm{~A} / 5 \mathrm{~A}}$ as well as an edge similarly intermediate between $\mathrm{Se}_{2 \mathrm{~B}}$ and $\mathrm{Se}_{3 \mathrm{~A} / 5 \mathrm{~A}}$. Qualitatively, these differences again suggest that $\mathrm{Se} 2 \mathrm{~B}$ engages in more covalent bonding to $\mathrm{Fe}$ than $\mathrm{Se} 3 \mathrm{~A} / 5 \mathrm{~A}$ and that the $\mathrm{Se} 3 \mathrm{~A} / 5 \mathrm{~A}$ position is electronically sensitive to $\mathrm{CO}$ binding at the distal edge of the cluster.

3.5. FeMoco Se HERFD EXAFS. The Se-substituted FeMoco samples were also analyzed by Se HERFD EXAFS to complement the local electronic structure information obtained from the Se HERFD XAS experiments with local metrical information (Figure 8). It can be immediately observed that the first $\mathrm{Se}-\mathrm{Fe}$ radial shell (radial distance $\sim 1.9 \AA$, non-phase-corrected) shifts to higher values going from $A v 1 S e_{l o}$ and $A v 1 S e_{h i}$ to $A v 1 S e_{\text {reac }}$ and Av1SeCO, suggesting the samples with greater $\mathrm{Se} 3 \mathrm{~A} / 5 \mathrm{~A}$ content exhibit longer average $\mathrm{Se}-\mathrm{Fe}$ distances. The EXAFS data were fit with multiple single-scattering paths including the first $\mathrm{Se}-\mathrm{Fe}$ radial shell, a $\mathrm{Se}-\mathrm{S}$ radial shell, and a second $\mathrm{Se}-\mathrm{Fe}^{\prime}$ radial shell (Figure S47-50). While fits omitting the long-range $\mathrm{Se}-\mathrm{S}$ and $\mathrm{Se}-\mathrm{Fe}^{\prime}$ scattering paths (Figures S51-54) afforded similar first

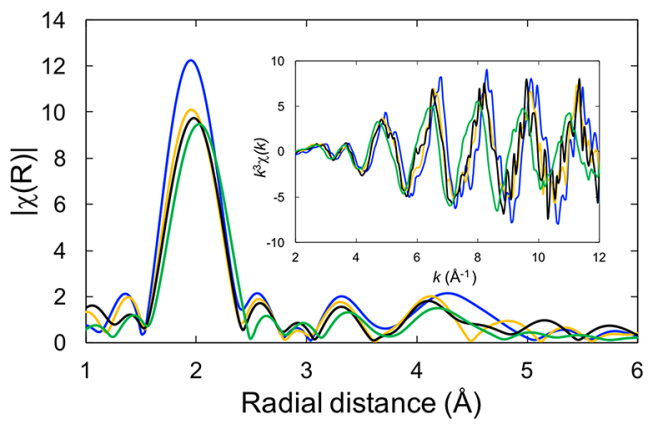

Figure 8. Non-phase-shifted Fourier transform of $k^{3}$-weighted Se HERFD EXAFS (with $k^{3}$-EXAFS inset) of Av1Se $e_{\text {lo }}$ (blue), Av1Se

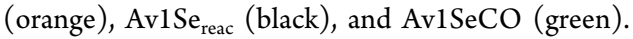

shell Se-Fe distances $( \pm 0.007 \AA)$, their inclusion resulted in improved fits with increased precision and decreased DebyeWaller-like disorder parameters $\left(\sigma^{2}\right)$ for the first $\mathrm{Se}-\mathrm{Fe}$ radial shell (Table S6). As shown in Table 3, the fit Se HERFD EXAFS data quantitatively reveal the clear trend observed in the first $\mathrm{Se}-\mathrm{Fe}$ scattering path, with the average $\mathrm{Se}-\mathrm{Fe}$ radial shell increasing from $2.314 \AA$ for $A v 1 S e_{l o}$ to $2.388 \AA$ for Av1SeCO. This observation is again consistent with Se2B engaging in a more covalent interaction with $\mathrm{Fe}$ compared to Se3A/5A.

Similar to the deconvolution of the Se HERFD XAS spectra, the average $\mathrm{Se}-\mathrm{Fe}$ distances of the $2 \mathrm{~B}$ and $3 \mathrm{~A} / 5 \mathrm{~A}$ positions were deconvoluted by solving the same systems of equations with the EXAFS-fitted average $\mathrm{Se}-\mathrm{Fe}$ distance used in place of the Se HERFD XAS spectra (Table 3). Again, the two sets of solutions were averaged and the difference reported as the error. The resultant values reveal a short average $\mathrm{Se}-\mathrm{Fe}$ distance of $2.29 \pm 0.02 \AA$ for $\mathrm{Se}_{2 \mathrm{~B}}$ and a significantly longer average $\mathrm{Se}-\mathrm{Fe}$ distance of $2.39 \pm 0.02 \AA$ for $\mathrm{Se}_{3 \mathrm{~A} / 5 \mathrm{~A}}$, which correlate well to the disparate pre-edge intensities observed by HERFD XAS. Noticeably, the average $\mathrm{Se}-\mathrm{Fe}$ distance of the $\mathrm{CO}$-inhibited $\mathrm{CO}-\mathrm{Se}_{3 \mathrm{~A} / 5 \mathrm{~A}}$ at $2.40 \pm 0.01 \AA$ is indistinguishable (within error) from the non-CO-inhibited $\mathrm{Se}_{3 \mathrm{~A} / 5 \mathrm{~A}}$ distance of $2.39 \pm 0.02 \AA$, suggesting that the observed differences in the $\mathrm{Se}_{3 \mathrm{~A} / 5 \mathrm{~A}}$ and $\mathrm{CO}-\mathrm{Se}_{3 \mathrm{~A} / 5 \mathrm{~A}}$ Se HERFD XAS spectra (in particular the pre-edge intensities) are dominated by electronic, rather than geometric, effects. The shorter $\mathrm{Se}-\mathrm{Fe}$ distance of $\mathrm{Se}_{2 \mathrm{~B}}$ is consistent with the average $\mathrm{Se} 2 \mathrm{~B}-\mathrm{Fe}$ distance observed crystallographically in Se2B-FeMoco $(2.30 \pm 0.03 \AA$ ), as well as $\mathrm{Se}-\mathrm{Fe}$ distances crystallographically observed in synthetic $\left[\mathrm{Fe}_{2} \mathrm{Se}_{2}\right]^{2+/ 1+}$ complexes of ca. 2.30-2.34 $\AA^{61-63}$ The significantly longer $\mathrm{Se}-\mathrm{Fe}$ distances of $\mathrm{Se}_{3 \mathrm{~A} / 5 \mathrm{~A}}$ and $\mathrm{CO}$ $\mathrm{Se}_{3 \mathrm{~A} / 5 \mathrm{~A}}$ suggest the presence of more reduced $\mathrm{Fe}$ centers, but secondary interactions from the protein environment could also be affecting the Se-Fe bonding.

3.6. Comparison to $\mathrm{S} X A S$ of $\left[\mathrm{Fe}_{2} \mathrm{~S}_{2}\right]^{n+}$ Series. In order to gain a more quantitative estimate of the $\mathrm{Fe}$ oxidation states at the Se bridge sites from the HERFD XAS spectra, a comparison was made to the $S$ XAS spectra of the previously reported $\left[\mathrm{Fe}_{2} \mathrm{~S}_{2}\right]^{2+/+/ 0}$ redox series (Table 1 and Figure S4). This series is unique in that it represents the only known, wellcharacterized synthetic $\mathrm{Fe}_{2} \mathrm{~S}_{2}$ system spanning all three redox states (diferric, mixed-valent, and diferrous), and thus offers the best comparison to the protein data. While the absolute pre-edge and edge energies cannot be directly compared between the $S$ and Se K-edge spectra, the relative metric $\left|\delta_{\mathrm{d}}\right|$ and pre-edge areas afford a natural contrast for the two 
Table 3. Parameters for Multicomponent Single Scattering Path Fits to Se HERFD EXAFS Data and Deconvoluted Average Se-Fe Distances at the $2 \mathrm{~B}$ and $3 \mathrm{~A} / 5 \mathrm{~A}$ Positions

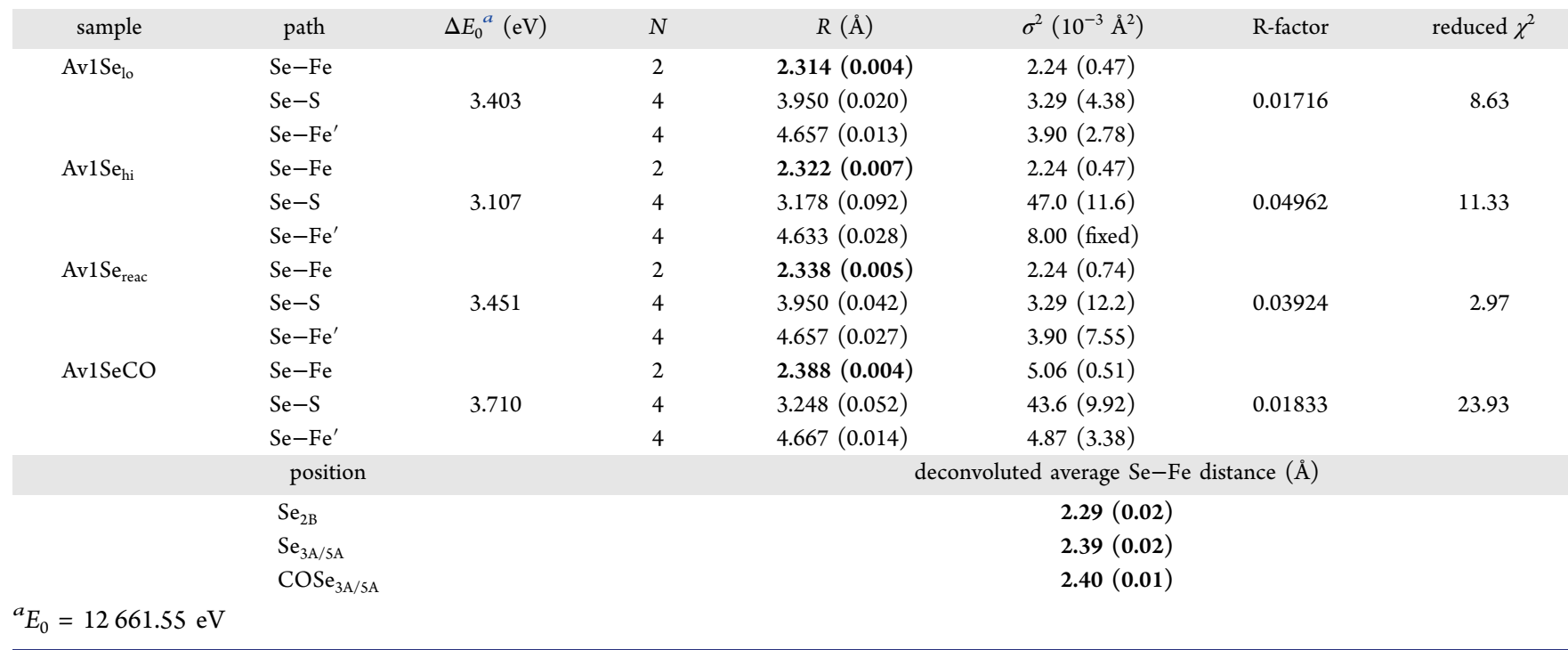

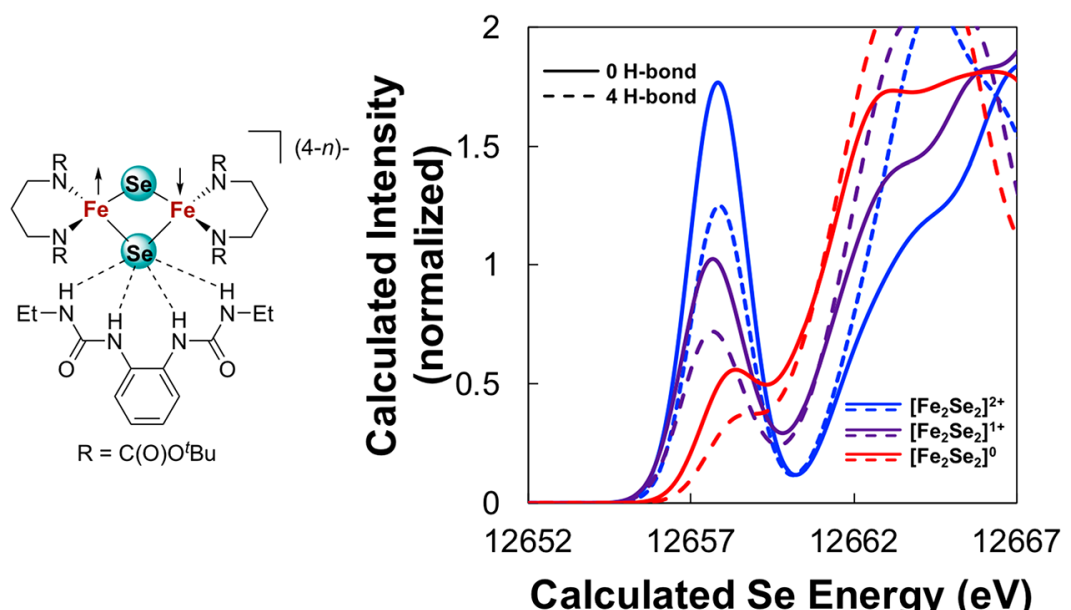

Figure 9. TDDFT calculations (right) of antiferromagnetically coupled $\left[\mathrm{Fe}_{2} \mathrm{Se}_{2}\right]^{n+}$ series (structure on left), where one selenide engages in hydrogen bonding to a bis-urea molecule (plotted dashed lines) and one selenide does not (plotted solid lines).

spectroscopies as supported by our TDDFT calculations, vide supra. Through comparison of both the pre-edge area and $\left|\delta_{\mathrm{d}}\right|$, it was observed that $\mathrm{Se}_{2 \mathrm{~B}}$ is most similar to the diferric $\left[\mathrm{Fe}_{2} \mathrm{~S}_{2}\right]^{2+}$, as both exhibit large pre-edge areas $(385 \pm 20$ vs $350)$ and large $\left|\delta_{\mathrm{d}}\right|$ values $(7.38 \pm 0.06$ and $7.25 \mathrm{eV})$. Both $\mathrm{Se}_{3 \mathrm{~A} / 5 \mathrm{~A}}$ and $\mathrm{CO}-\mathrm{Se}_{3 \mathrm{~A} / 5 \mathrm{~A}}$ have smaller relative $\mathrm{Fe} 3 \mathrm{~d}$-manifold energies $(5.76 \pm 0.04$ and $5.95 \pm 0.08 \mathrm{eV})$ more consistent with the diferrous $\left[\mathrm{Fe}_{2} \mathrm{~S}_{2}\right]^{0}$ complex $(6.27 \mathrm{eV})$, though the preedge intensities are what most differentiates the two. The greater intensity of $\mathrm{CO}-\mathrm{Se}_{3 \mathrm{~A} / 5 \mathrm{~A}}(245 \pm 10)$ is most similar to the mixed-valent $\left[\mathrm{Fe}_{2} \mathrm{~S}_{2}\right]^{+}$complex (260), while the smaller pre-edge of $\mathrm{Se}_{3 \mathrm{~A} / 5 \mathrm{~A}}(130 \pm 30)$ better matches that of the diferrous $\left[\mathrm{Fe}_{2} \mathrm{~S}_{2}\right]^{0}$ complex (180). These comparisons suggest that the features of the $\mathrm{Se}_{2 \mathrm{~B}}$ spectrum are most consistent with a Se bridging two $\mathrm{Fe}^{3+}$ centers, while the $\mathrm{CO}-\mathrm{Se}_{3 \mathrm{~A} / 5 \mathrm{~A}}$ features are more consistent with an average oxidation state of $\mathrm{Fe}^{2.5+}$ and the $\mathrm{Se}_{3 \mathrm{~A} / 5 \mathrm{~A}}$ features suggests an average oxidation state of $\mathrm{Fe}^{2+}$. It should be cautioned, however, that these comparisons to synthetic model complexes fail to take into account the effects of electrostatic and hydrogen bonding interactions present in the protein, which may be significant.
3.7. Probing Electrostatic and Hydrogen Bonding Effects through Small Molecule TDDFT Calculations. In order to quantitatively estimate the effects of hydrogen bonding on the Se XAS spectrum, we turned to TDDFT calculations of a fictitious $\left[\mathrm{Fe}_{2} \mathrm{Se}_{2}\right]^{n+}$ series in which one of the selenide bridges is hydrogen bonding with a bis-urea small molecule to simulate the interactions of the Se3A position with the neighboring protein residues (Figure 9 and Table 4). As only one of the bridging selenides is engaged in hydrogen

Table 4. Calculated Se XAS Pre-edge Areas and Relative Fe 3d-Manifold Energies in H-Bonded Dimer

$\begin{array}{ccccc}\text { sample } & \begin{array}{c}\text { spin- } \\ \text { state }\end{array} & \begin{array}{c}\mathrm{H} \text { - } \\ \text { bonds }\end{array} & \begin{array}{c}\text { calculated pre-edge } \\ \text { area }(\text { a.u. })\end{array} & \begin{array}{c}\text { calculated } \\ \left|\delta_{\mathrm{d}}\right|(\mathrm{eV})\end{array} \\ \text { bis-urea }+\left[\mathrm{Fe}_{2} \mathrm{Se}_{2}\right]^{2+} & 0 & 0 & 390 & 10.10 \\ \text { bis-urea }+\left[\mathrm{Fe}_{2} \mathrm{Se}_{2}\right]^{1+} & 1 / 2 & 0 & 275 & 6.60 \\ & & 4 & 245 & 10.00 \\ \text { bis-urea }+\left[\mathrm{Fe}_{2} \mathrm{Se}_{2}\right]^{0} & 0 & 0 & 175 & 7.60 \\ & & 4 & 90 & 8.30 \\ & & 60 & 6.20\end{array}$


bonding, the second selenide can be used as a control to directly compare the effects of the hydrogen bonding interaction. Our computations reveal that at every oxidation state (diferric/mixed-valent/diferrous), the hydrogen bonding interaction resulted in a decrease in pre-edge intensity, nearly equivalent to the effect of one-electron reduction of the dimer (a decrease in the average iron oxidation state by 0.5 units). While the presence of the hydrogen bonding interaction results in significant geometric distortions to the $\left[\mathrm{Fe}_{2} \mathrm{Se}_{2}\right]$ core, we found that the geometric changes do not fully account for the observed changes in pre-edge intensity, as maintaining the geometric distortion while removing the hydrogen bond donor results in regaining a significant portion of the pre-edge intensity lost due to hydrogen bonding. This is consistent with our earlier calculations that reveal negligible geometric effect on ligand pre-edge intensity and further supports our interpretation of the differences between the $\mathrm{Se}_{3 \mathrm{~A} / 5 \mathrm{~A}}$ and $\mathrm{CO}-\mathrm{Se}_{3 \mathrm{~A} / 5 \mathrm{~A}}$ spectra as largely arising from electronic rather than geometric perturbations.

Furthermore, we sought to briefly explore electrostatic effects on Se XAS. The diferric complex $\left[\mathrm{Et}_{4} \mathrm{~N}\right]_{2}\left[\mathrm{Fe}_{2} \mathrm{Se}_{2}(\mathrm{SPh})_{4}\right]$ afforded a convenient combined experimental and computational case study, as the crystal structure exhibits two tetraethylammonium cations in relatively close proximity to each $\mathrm{Se}$ atom ( $\mathrm{Se}-\mathrm{N}$ distances of ca. $5 \AA$ ). As previously discussed, the experimental spectrum of $\left[\mathrm{Et}_{4} \mathrm{~N}\right]_{2}\left[\mathrm{Fe}_{2} \mathrm{Se}_{2}(\mathrm{SPh})_{4}\right]$ reveals an intense pre-edge (area = $385)$ consistent with our earlier calculations and comparisons to the S XAS data of synthetic analogues, though the $\left|\delta_{\mathrm{d}}\right|$ value $(6.10 \mathrm{eV})$ is slightly lower than anticipated for a diferric site when compared to model S XAS data. TDDFT calculations of the $\left[\mathrm{Fe}_{2} \mathrm{Se}_{2}(\mathrm{SPh})_{4}\right]^{2-}$ dianion (Figure 10, solid blue line)

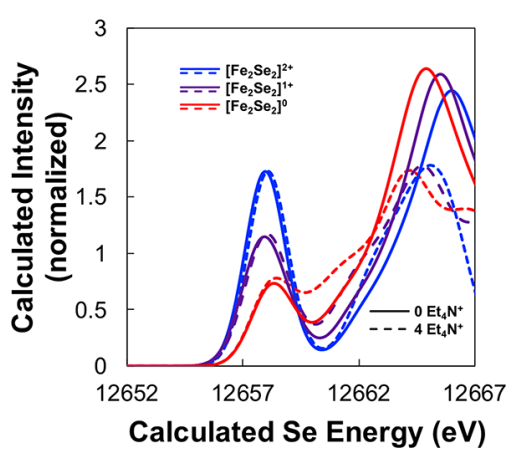

Figure 10. TDDFT calculated Se XAS spectra of antiferromagnetically coupled $\left[\mathrm{Fe}_{2} \mathrm{Se}_{2}(\mathrm{SPh})_{4}\right]^{(4-n)-}$ series $(n=2,1,0)$ in the absence (solid lines) and in the presence (dashed lines) of the four crystallographically nearest $\mathrm{Et}_{4} \mathrm{~N}^{+}$cations observed in $\left[\mathrm{Et}_{4} \mathrm{~N}\right]_{2}\left[\mathrm{Fe}_{2} \mathrm{Se}_{2}(\mathrm{SPh})_{4}\right]$, demonstrating the inclusion of the cations decreases $\left|\delta_{\mathrm{d}}\right|$ for all oxidation states. All calculations performed on the crystal structure of $\left[\mathrm{Et}_{4} \mathrm{~N}\right]_{2}\left[\mathrm{Fe}_{2} \mathrm{Se}_{2}(\mathrm{SPh})_{4}\right]$ with geometry-optimized hydrogen atoms. reveal the expected intense pre-edge feature and large $\left|\delta_{\mathrm{d}}\right|$ splitting (Table 5) consistent with our earlier calculations for a diferric dimer, suggesting a $\left|\delta_{\mathrm{d}}\right|$ somewhat larger than what is observed experimentally. However, when we explicitly include the four nearest $\left[\mathrm{Et}_{4} \mathrm{~N}\right]^{+}$cations in our TDDFT calculation (Figure 10, dashed blue line), the pre-edge intensity remains relatively unperturbed, while $\left|\delta_{\mathrm{d}}\right|$ decreases by ca. $1 \mathrm{eV}$. This effect is observed across all oxidation states, though it is most pronounced at the diferric level. These relatively simplistic calculations suggest that while electrostatic interactions will have a negligible effect on pre-edge intensity, the perturbation of the rising edge may be significant. Though a more comprehensive experimental and theoretical study on bridging selenide systems will be necessary to better quantify the effects of such secondary interactions on the Se K-edge spectrum, the present results emphasize the utility of Se HERFD XAS for selectively probing the belt positions in FeMoco and further demonstrate the sensitivity of the Se spectra to the bound CO substrate.

3.8. FeMoco Electronic Structure Picture. The results of the Se HERFD XAS experiments on Se-substituted FeMoco reveal the presence of significant asymmetry in the electronic structure of the nitrogenase cofactor, with the $\mathrm{Fe} 2 / \mathrm{Fe} 6$ edge exhibiting more local oxidized character while the $\mathrm{Fe} 4 / \mathrm{Fe} 5$ / $\mathrm{Fe} 3 / \mathrm{Fe} 7$ face exhibits more reduced character. This electronic asymmetry is consistent with the structural asymmetry observed crystallographically at the three bridging sulfide positions (Figure 11), wherein protein-cofactor interactions break the formal 3-fold symmetry of the metallocofactor and likely contribute to significant charge localization. Specifically, it has been rationalized that the positive charges of the two conserved arginine residues, R96 and R359, located in close proximity to the $5 \mathrm{~A}$ bridge position could help to stabilize local ferrous character at $\mathrm{Fe} 3$ and Fe $7 .{ }^{16}$ Similarly, we hypothesize that the four amide groups of R359, L358, G357, and G356 engage in hydrogen bonding to the $3 \mathrm{~A}$ bridge position and that these interactions could stabilize a more locally reduced state at $\mathrm{Fe} 4$ and $\mathrm{Fe} 5$. It has previously been shown that hydrogen bonding interactions to thiolate ligands in both protein ${ }^{6,65}$ and synthetic model complexes ${ }^{66-68}$ can significantly shift the reduction potentials of bound $\mathrm{Fe}$ centers, with increasing hydrogen bonding interactions resulting in increasing shifts in reduction potentials. Thus, these two sets of interactions (electrostatic and hydrogen bonding) at the 3A and 5A bridge positions are anticipated to localize charge density to the $\mathrm{Fe} 4$ / $\mathrm{Fe} 5 / \mathrm{Fe} 3 / \mathrm{Fe} 7$ face of the cofactor, while the weaker single hydrogen bond interaction at the $2 \mathrm{~B}$ bridge position with histidine H195 would favor a more locally oxidized Fe2/Fe6 edge. This interpretation is also consistent with the Se HERFD EXAFS data, which reveals a shorter average Se-Fe distance at the $2 \mathrm{~B}$ position and a significantly longer average $\mathrm{Se}-\mathrm{Fe}$ distance at the $3 \mathrm{~A} / 5 \mathrm{~A}$ positions.

Table 5. Calculated and Experimental Se XAS Pre-edge Areas and Relative Fe 3d-Manifold Energies for $\left[\mathrm{Fe}_{2} \mathrm{Se}_{2}\right]^{n+}$

\begin{tabular}{|c|c|c|c|c|c|}
\hline sample & spin-state & calculated pre-edge area (a.u.) & calculated $\left|\delta_{\mathrm{d}}\right|(\mathrm{eV})$ & experimental pre-edge area (a.u.) & experimental $\left|\delta_{\mathrm{d}}\right|(\mathrm{eV})$ \\
\hline$\left[\mathrm{Fe}_{2} \mathrm{Se}_{2}(\mathrm{SPh})_{4}\right]^{2-}$ & 0 & 375 & 8.10 & 385 & 6.05 \\
\hline$\left\{\left[\mathrm{Et}_{4} \mathrm{~N}\right]_{4}\left[\mathrm{Fe}_{2} \mathrm{Se}_{2}(\mathrm{SPh})_{4}\right]\right\}^{2+}$ & 0 & 380 & 7.00 & - & - \\
\hline$\left[\mathrm{Fe}_{2} \mathrm{Se}_{2}(\mathrm{SPh})_{4}\right]^{3-}$ & $1 / 2$ & 285 & 7.60 & - & - \\
\hline$\left\{\left[\mathrm{Et}_{4} \mathrm{~N}\right]_{4}\left[\mathrm{Fe}_{2} \mathrm{Se}_{2}(\mathrm{SPh})_{4}\right]\right\}^{1+}$ & $1 / 2$ & 280 & 6.70 & - & - \\
\hline$\left[\mathrm{Fe}_{2} \mathrm{Se}_{2}(\mathrm{SPh})_{4}\right]^{4-}$ & 0 & 145 & 6.70 & - & - \\
\hline$\left\{\left[\mathrm{Et}_{4} \mathrm{~N}\right]_{4}\left[\mathrm{Fe}_{2} \mathrm{Se}_{2}(\mathrm{SPh})_{4}\right]\right\}^{0}$ & 0 & 135 & 6.00 & - & - \\
\hline
\end{tabular}




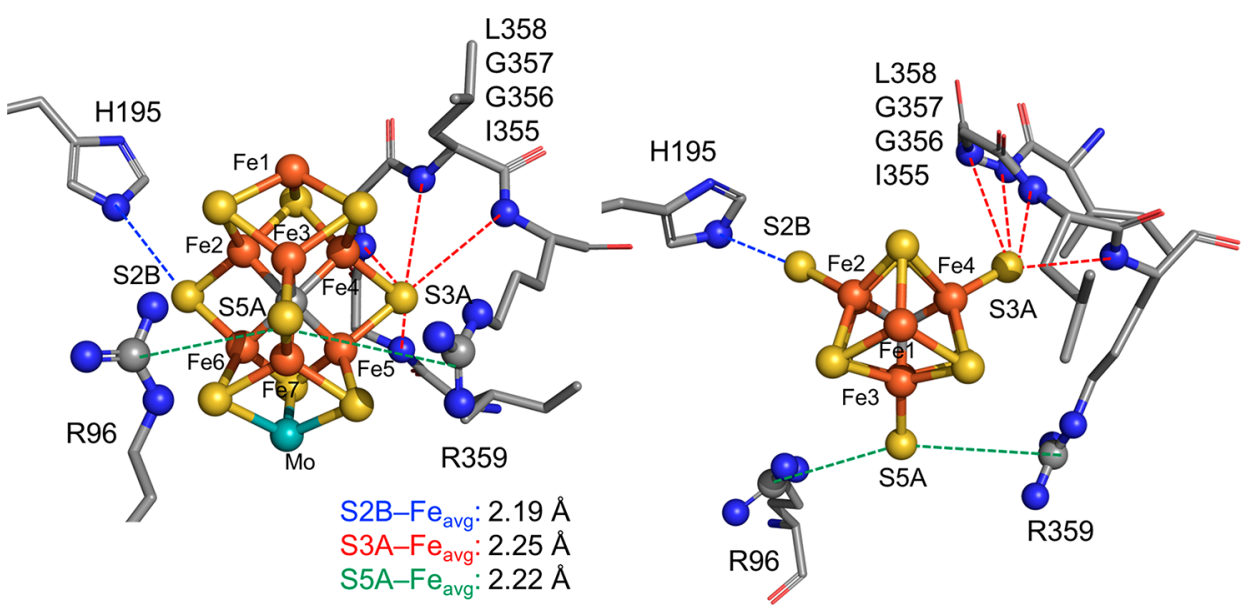

Figure 11. Asymmetric FeMoco-protein interactions in profile (left) and Fe1-Mo top-down view (right) from A. vinelandii (PDB-ID 3U7Q). Nearest interactions to the bridging positions 2B (blue), 3A (red), and 5A (green) are emphasized as dashed lines. Reported S-Fe distances are averages of both clusters in the crystallographic asymmetric unit. Cofactor ligands C275, H442, and homocitrate are omitted for clarity. Nitrogen atoms are shown in blue, oxygen in red, and carbon in gray.

The experimental Se HERFD XAS data coupled with the results from TDDFT calculations on small molecule model systems support assignment of $\mathrm{Se} 2 \mathrm{~B}$ as bridging two ferric $\mathrm{Fe}$ centers whose spins are aligned antiparallel with respect to one another. This oxidation state assignment for $\mathrm{Fe} 2 / \mathrm{Fe} 6$ is consistent with the previous SpReAD study, ${ }^{16}$ while the relative coupling assignment is consistent with recent QM/ $\mathrm{MM}$ calculations on FeMoco. ${ }^{20}$ We emphasize that this is the first experimental data to reveal relative coupling between the $\mathrm{Fe}$ centers of FeMoco. Additionally, taking into account the relative effects of electrostatic and hydrogen bonding interactions on the Se K-edge absorption features, the experimental Se HERFD XAS data are suggestive of an average $\mathrm{Fe}$ oxidation state in the range of ca. $+2.25-2.5$ for the $\mathrm{Fe} 4 / \mathrm{Fe} 5 / \mathrm{Fe} 3 / \mathrm{Fe} 7$ face in the resting state. This oxidation state assignment could be consistent with either the fully localized assignment of the SpReAD study or the more delocalized assignment of the $\mathrm{QM} / \mathrm{MM}$ studies. The similar Seoccupancies of the $3 \mathrm{~A}$ and $5 \mathrm{~A}$ positions in the present data limits our ability to further distinguish between these two proposals, but in the future such a determination may be feasible if samples with sufficiently disparate $3 \mathrm{~A}$ and $5 \mathrm{~A}$ populations can be prepared (the initial Se migration data ${ }^{21}$ suggests this is theoretically possible).

Our results also suggest that upon $\mathrm{CO}$ binding to the cluster, the $\mathrm{Fe} 4 / \mathrm{Fe} 5 / \mathrm{Fe} 3 / \mathrm{Fe} 7$ face of the cofactor is electronically perturbed, appearing more oxidized. This initially seems counterintuitive, as it is known $\mathrm{CO}$ does not react with the cofactor in the resting state, but requires a more reduced state of FeMoco to bind (presumably $E_{2}{ }^{69}$ where $E_{0}$ refers to the resting state and $E_{n}$ refers to the $n$-electron reduced state for $n$ $=1,2,3$, etc.). However, it is unclear whether or not following $\mathrm{CO}$ binding the cofactor remains in a reduced state or if it can relax back to an $E_{0^{-}}$or $E_{1}$-equivalent state, as proton reduction remains uninhibited by $\mathrm{CO}$. Additionally, while a number of CO-inhibited states have been identified by EPR that are proposed to differ by the mode and number of the $\mathrm{Fe}-\mathrm{CO}$ interactions (lo-CO, hi-CO, etc.), it has also been observed that EPR-silent species are also present during reaction with $\mathrm{CO}$, suggestive of an $E_{1}$-equivalent state being generated. ${ }^{70-72}$ The observation that $\mathrm{CO}-\mathrm{Se}_{3 \mathrm{~A} / 5 \mathrm{~A}}$ appears more oxidized than $\mathrm{Se}_{3 \mathrm{~A} / 5 \mathrm{~A}}$ could be explained by a redox reorganization within the cofactor, whereby electron density is shifted from the Fe4/ $\mathrm{Fe} 5 / \mathrm{Fe} 3 / \mathrm{Fe} 7$ face to the $\mathrm{Fe} 2 / \mathrm{Fe} 6$ edge where $\mathrm{CO}$ binds. Recently, redox reorganization upon CO-binding was observed in an electronically localized synthetic $\left[\mathrm{Fe}_{4} \mathrm{O}\right]^{8+}$ cluster, wherein an electron is transferred from a local $\mathrm{Fe}^{2+}$ center to a formerly $\mathrm{Fe}^{3+}$ center to facilitate $\mathrm{CO}$ binding. ${ }^{73}$ We speculate that such a redox reorganization mechanism in FeMoco would likely be facilitated by the highly covalent carbide, suggesting a plausible role for the central atom during catalysis. Alternatively, a change in the relative coupling across Se3A and Se5A could also account for the observed differences in $\mathrm{Se}_{3 \mathrm{~A} / 5 \mathrm{~A}}$ and $\mathrm{CO}-\mathrm{Se}_{3 \mathrm{~A} / 5 \mathrm{~A}}$, as our TDDFT calculations on model systems have shown increased pre-edge intensity for antiferromagnetically coupled centers relative to ferromagnetic centers. Even in the localized limit, these results suggest that the electronic structure of the cluster may be more dynamic than previously assumed, further emphasizing the necessity for development of spectroscopic methods capable of extracting local electronic structure information from FeMoco, particularly under turnover conditions.

\section{CONCLUSIONS}

The present study demonstrates a new method for probing the local electronic structure of FeMoco and reveals a significant asymmetry with regard to the electronic distribution about the cluster. Analysis of Se HERFD XAS spectra of Se-substituted FeMoco indicate that the $2 \mathrm{~B}$ and $3 \mathrm{~A} / 5 \mathrm{~A}$ bridging positions of FeMoco are electronically distinct, with the $\mathrm{Fe} 2 / \mathrm{Fe} 6$ edge consistent with an antiferromagnetically coupled diferric pair, while the $\mathrm{Fe} 3 / \mathrm{Fe} 4 / \mathrm{Fe} 5 / \mathrm{Fe} 7$ face of the cofactor exhibits more localized ferrous character. Additionally, we have demonstrated that this technique can be extended beyond the resting state of nitrogenase through analysis of Se-substituted CO-inhibited FeMoco, and observed that the electronic structure of the Fe3/ $\mathrm{Fe} 4 / \mathrm{Fe} 5 / \mathrm{Fe} 7$ face is electronically, but not geometrically, sensitive to binding of $\mathrm{CO}$ to the distal edge of the cofactor. A redox reorganization mechanism within the cluster has been postulated to account for the observed electronic perturbation upon $\mathrm{CO}$ binding. Further studies incorporating synthetic FeSe model complexes and advanced theoretical methods are currently underway in our laboratories to further exploit Se 
substitution in elucidating the local electronic structure of FeMoco.

\section{ASSOCIATED CONTENT}

\section{S Supporting Information}

The Supporting Information is available free of charge on the ACS Publications website at DOI: 10.1021/jacs.9b06988.

Detailed protein preparations, summaries of crystallographic data, fits of experimental spectra, and computational details (PDF)

\section{AUTHOR INFORMATION}

\section{Corresponding Authors}

*E-mail: dcrees@caltech.edu.

*E-mail: serena.debeer@cec.mpg.de.

ORCID

Justin T. Henthorn: 0000-0003-4876-2680

Renee J. Arias: 0000-0002-6505-7513

Uwe Bergmann: 0000-0001-5639-166X

Douglas C. Rees: 0000-0003-4073-1185

Serena DeBeer: 0000-0002-5196-3400

\section{Author Contributions}

\#J.T.H. and R.J.A. contributed equally.

\section{Notes}

The authors declare no competing financial interest.

Crystallographic data has been uploaded to the PDB.

\section{ACKNOWLEDGMENTS}

J.T.H. and S.D. thank the Max Planck Society for funding. S.D. acknowledges funding from the European Research Council under the European Union's Seventh Framework Programme (FP/2007-2013)/ERC Grant Agreement No. 615414 and the DFG SPP 1927 "Iron Sulfur for Life" project (Project No. DE 1877/1-1). J.T.H. acknowledges funding from the Alexander von Humboldt Foundation. S.K. would like to thank The Knut and Alice Wallenberg Foundation (KAW 2014.0370) for financial support. We are grateful to Dr. T. Weyhermüller and T. Mußfeldt for supplying $\left[\mathrm{Et}_{4} \mathrm{~N}\right]_{2}\left[\mathrm{Fe}_{2} \mathrm{Se}_{2}(\mathrm{SPh})_{4}\right]$. We thank the Gordon and Betty Moore Foundation and the Beckman Institute at Caltech for their generous support of the Molecular Observatory at Caltech, the staff of SSRL BL12-2 for their technical assistance. Support from NIH Grant GM045162 and the Howard Hughes Medical Institute to D.C.R. and from NIH Training Grant T32GM7616 to R.J.A. is gratefully acknowledged. Use of the Stanford Synchrotron Radiation Lightsource, SLAC National Accelerator Laboratory, is supported by the U.S. Department of Energy, Office of Basic Energy Sciences, under Contract No. DE-AC02-76SF00515. The SSRL Structural Molecular Biology Program is supported by the DOE Office of Biological and Environmental Research and by the National Institutes of Health, National Institute of General Medical Sciences (including P41GM103393). The contents of this publication are solely the responsibility of the authors and do not necessarily represent the official views of NIGMS or NIH. We thank Paul Oyala and the Electron Paramagnetic Resonance Facility at Caltech for assistance with EPR measurements.

\section{REFERENCES}

(1) Canfield, D. E.; Glazer, A. N.; Falkowski, P. G. The Evolution and Future of Earth's Nitrogen Cycle. Science 2010, 330 (6001), 192.
(2) Gruber, N.; Galloway, J. N. An Earth-system perspective of the global nitrogen cycle. Nature 2008, 451, 293.

(3) Lee, C. C.; Hu, Y.; Ribbe, M. W. Vanadium Nitrogenase Reduces CO. Science 2010, 329 (5992), 642.

(4) Schlögl, R. Catalytic Synthesis of Ammonia-A "Never-Ending Story"? Angew. Chem., Int. Ed. 2003, 42 (18), 2004-2008.

(5) Rofer-DePoorter, C. K. A comprehensive mechanism for the Fischer-Tropsch synthesis. Chem. Rev. 1981, 81 (5), 447-474.

(6) Hoffman, B. M.; Lukoyanov, D.; Yang, Z.-Y.; Dean, D. R.; Seefeldt, L. C. Mechanism of Nitrogen Fixation by Nitrogenase: The Next Stage. Chem. Rev. 2014, 114 (8), 4041-4062.

(7) Yoo, S. J.; Angove, H. C.; Papaefthymiou, V.; Burgess, B. K.; Münck, E. Mössbauer Study of the MoFe Protein of Nitrogenase from Azotobacter vinelandii Using Selective 57Fe Enrichment of the MCenters. J. Am. Chem. Soc. 2000, 122 (20), 4926-4936.

(8) Kowalska, J.; DeBeer, S. The role of X-ray spectroscopy in understanding the geometric and electronic structure of nitrogenase. Biochim. Biophys. Acta, Mol. Cell Res. 2015, 1853 (6), 1406-1415.

(9) Lima, F. A.; Bjornsson, R.; Weyhermuller, T.; Chandrasekaran, P.; Glatzel, P.; Neese, F.; DeBeer, S. High-resolution molybdenum Kedge X-ray absorption spectroscopy analyzed with time-dependent density functional theory. Phys. Chem. Chem. Phys. 2013, 15 (48), 20911-20920.

(10) Kowalska, J. K.; Henthorn, J. T.; Van Stappen, C.; Trncik, C.; Einsle, O.; Keavney, D.; DeBeer, S. X-ray Magnetic Circular Dichroism Spectroscopy Applied to Nitrogenase and Related Models: Experimental Evidence for a Spin-Coupled Molybdenum(III) Center. Angew. Chem., Int. Ed. 2019, 58 (28), 9373-9377.

(11) Rees, J. A.; Bjornsson, R.; Kowalska, J. K.; Lima, F. A.; Schlesier, J.; Sippel, D.; Weyhermuller, T.; Einsle, O.; Kovacs, J. A.; DeBeer, S. Comparative electronic structures of nitrogenase FeMoco and FeVco. Dalton Transactions 2017, 46 (8), 2445-2455.

(12) Hoffman, B. M. ENDOR and ESEEM of a Non-Kramers Doublet in an Integer-Spin System. J. Phys. Chem. 1994, 98 (45), 11657-11665.

(13) Lukoyanov, D.; Yang, Z.-Y.; Barney, B. M.; Dean, D. R.; Seefeldt, L. C.; Hoffman, B. M. Unification of reaction pathway and kinetic scheme for $\mathrm{N} 2$ reduction catalyzed by nitrogenase. Proc. Natl. Acad. Sci. U. S. A. 2012, 109 (15), 5583.

(14) Sturgeon, B. E.; Doan, P. E.; Liu, K. E.; Burdi, D.; Tong, W. H.; Nocek, J. M.; Gupta, N.; Stubbe, J.; Kurtz, D. M.; Lippard, S. J.; Hoffman, B. M. Non-Kramers ESEEM of Integer-Spin Diferrous Carboxylate-Bridged Clusters in Proteins. J. Am. Chem. Soc. 1997, 119 (2), 375-386.

(15) Spatzal, T.; Einsle, O.; Andrade, S. L. A. Analysis of the Magnetic Properties of Nitrogenase FeMo Cofactor by Single-Crystal EPR Spectroscopy. Angew. Chem., Int. Ed. 2013, 52 (38), 1011610119.

(16) Spatzal, T.; Schlesier, J.; Burger, E.-M.; Sippel, D.; Zhang, L.; Andrade, S. L. A.; Rees, D. C.; Einsle, O. Nitrogenase FeMoco investigated by spatially resolved anomalous dispersion refinement. Nat. Commun. 2016, 7, 10902.

(17) Bjornsson, R.; Neese, F.; DeBeer, S. Revisiting the Mössbauer Isomer Shifts of the FeMoco Cluster of Nitrogenase and the Cofactor Charge. Inorg. Chem. 2017, 56 (3), 1470-1477.

(18) Beinert, H.; Holm, R. H.; Münck, E. Iron-Sulfur Clusters: Nature's Modular, Multipurpose Structures. Science 1997, 277 (5326), 653.

(19) Noodleman, L.; Peng, C. Y.; Case, D. A.; Mouesca, J. M. Orbital interactions, electron delocalization and spin coupling in ironsulfur clusters. Coord. Chem. Rev. 1995, 144, 199-244.

(20) Benediktsson, B.; Bjornsson, R. QM/MM Study of the Nitrogenase MoFe Protein Resting State: Broken-Symmetry States, Protonation States, and QM Region Convergence in the FeMoco Active Site. Inorg. Chem. 2017, 56 (21), 13417-13429.

(21) Spatzal, T.; Perez, K. A.; Howard, J. B.; Rees, D. C. Catalysisdependent selenium incorporation and migration in the nitrogenase active site iron-molybdenum cofactor. eLife 2015, 4, No. e11620. 
(22) Perez, K. A. Ph.D. Thesis, California Institute of Technology, Pasadena, 2016

(23) Spatzal, T.; Perez, K. A.; Einsle, O.; Howard, J. B.; Rees, D. C. Ligand binding to the FeMo-cofactor: Structures of CO-bound and reactivated nitrogenase. Science 2014, 345 (6204), 1620-1623.

(24) Sokaras, D.; Weng, T. C.; Nordlund, D.; Alonso-Mori, R.; Velikov, P.; Wenger, D.; Garachtchenko, A.; George, M.; Borzenets, V.; Johnson, B.; Rabedeau, T.; Bergmann, U. A seven-crystal Johanntype hard $\mathrm{x}$-ray spectrometer at the Stanford Synchrotron Radiation Lightsource. Rev. Sci. Instrum. 2013, 84 (5), No. 053102.

(25) Ravel, B.; Newville, M. ATHENA, ARTEMIS, HEPHAESTUS: data analysis for X-ray absorption spectroscopy using IFEFFIT. J. Synchrotron Radiat. 2005, 12 (4), 537-541.

(26) DeBeer George, S.; Neese, F. Calibration of Scalar Relativistic Density Functional Theory for the Calculation of Sulfur K-Edge X-ray Absorption Spectra. Inorg. Chem. 2010, 49 (4), 1849-1853.

(27) DeBeer George, S.; Petrenko, T.; Neese, F. Time-dependent density functional calculations of ligand K-edge X-ray absorption spectra. Inorg. Chim. Acta 2008, 361 (4), 965-972.

(28) Neese, F. Prediction of molecular properties and molecular spectroscopy with density functional theory: From fundamental theory to exchange-coupling. Coord. Chem. Rev. 2009, 253 (5), 526563.

(29) Neese, F. The ORCA program system. Wiley Interdisciplinary Reviews: Computational Molecular Science 2012, 2 (1), 73-78.

(30) Staroverov, V. N.; Scuseria, G. E.; Tao, J.; Perdew, J. P. Comparative assessment of a new nonempirical density functional: Molecules and hydrogen-bonded complexes. J. Chem. Phys. 2003, 119 (23), 12129-12137.

(31) Tao, J.; Perdew, J. P.; Staroverov, V. N.; Scuseria, G. E. Climbing the Density Functional Ladder: Nonempirical MetaGeneralized Gradient Approximation Designed for Molecules and Solids. Phys. Rev. Lett. 2003, 91 (14), 146401.

(32) Grimme, S.; Antony, J.; Ehrlich, S.; Krieg, H. A consistent and accurate $\mathrm{ab}$ initio parametrization of density functional dispersion correction (DFT-D) for the 94 elements H-Pu. J. Chem. Phys. 2010, 132 (15), 154104.

(33) Grimme, S.; Ehrlich, S.; Goerigk, L. Effect of the damping function in dispersion corrected density functional theory. J. Comput. Chem. 2011, 32 (7), 1456-1465.

(34) Lenthe, E. v.; Baerends, E. J.; Snijders, J. G. Relativistic regular two-component Hamiltonians. J. Chem. Phys. 1993, 99 (6), 45974610.

(35) van Wüllen, C. Molecular density functional calculations in the regular relativistic approximation: Method, application to coinage metal diatomics, hydrides, fluorides and chlorides, and comparison with first-order relativistic calculations. J. Chem. Phys. 1998, 109 (2), 392-399.

(36) Pantazis, D. A.; Chen, X.-Y.; Landis, C. R.; Neese, F. AllElectron Scalar Relativistic Basis Sets for Third-Row Transition Metal Atoms. J. Chem. Theory Comput. 2008, 4 (6), 908-919.

(37) Weigend, F.; Ahlrichs, R. Balanced basis sets of split valence, triple zeta valence and quadruple zeta valence quality for $\mathrm{H}$ to $\mathrm{Rn}$ : Design and assessment of accuracy. Phys. Chem. Chem. Phys. 2005, 7 (18), 3297-3305.

(38) Izsák, R.; Neese, F. An overlap fitted chain of spheres exchange method. J. Chem. Phys. 2011, 135 (14), 144105.

(39) Neese, F.; Wennmohs, F.; Hansen, A.; Becker, U. Efficient, approximate and parallel Hartree-Fock and hybrid DFT calculations. A 'chain-of-spheres' algorithm for the Hartree-Fock exchange. Chem. Phys. 2009, 356 (1), 98-109.

(40) Kowalska, J. K.; Hahn, A. W.; Albers, A.; Schiewer, C. E.; Bjornsson, R.; Lima, F. A.; Meyer, F.; DeBeer, S. X-ray Absorption and Emission Spectroscopic Studies of [L2Fe2S2]n Model Complexes: Implications for the Experimental Evaluation of Redox States in Iron-Sulfur Clusters. Inorg. Chem. 2016, 55 (9), 4485-4497.

(41) Glaser, T.; Hedman, B.; Hodgson, K. O.; Solomon, E. I. Ligand K-Edge X-ray Absorption Spectroscopy: A Direct Probe of LigandMetal Covalency. Acc. Chem. Res. 2000, 33 (12), 859-868.
(42) Solomon, E. I.; Hedman, B.; Hodgson, K. O.; Dey, A.; Szilagyi, R. K. Ligand K-edge X-ray absorption spectroscopy: covalency of ligand-metal bonds. Coord. Chem. Rev. 2005, 249 (1), 97-129.

(43) Dey, A.; Jenney, F. E.; Adams, M. W. W.; Johnson, M. K.; Hodgson, K. O.; Hedman, B.; Solomon, E. I. Sulfur K-Edge X-ray Absorption Spectroscopy and Density Functional Theory Calculations on Superoxide Reductase: Role of the Axial Thiolate in Reactivity. J. Am. Chem. Soc. 2007, 129 (41), 12418-12431.

(44) Dey, A.; Jiang, Y.; Ortiz de Montellano, P.; Hodgson, K. O.; Hedman, B.; Solomon, E. I. S K-edge XAS and DFT Calculations on Cytochrome P450: Covalent and Ionic Contributions to the CysteineFe Bond and Their Contribution to Reactivity. J. Am. Chem. Soc. 2009, 131 (22), 7869-7878.

(45) Dey, A.; Peng, Y.; Broderick, W. E.; Hedman, B.; Hodgson, K. O.; Broderick, J. B.; Solomon, E. I. S K-edge XAS and DFT Calculations on SAM Dependent Pyruvate Formate-Lyase Activating Enzyme: Nature of Interaction between the Fe4S4 Cluster and SAM and its Role in Reactivity. J. Am. Chem. Soc. 2011, 133 (46), 1865618662.

(46) Dey, A.; Roche, C. L.; Walters, M. A.; Hodgson, K. O.; Hedman, B.; Solomon, E. I. Sulfur K-Edge XAS and DFT Calculations on [Fe4S4]2+ Clusters: Effects of H-bonding and Structural Distortion on Covalency and Spin Topology. Inorg. Chem. 2005, 44 (23), 8349-8354.

(47) Glaser, T.; Rose, K.; Shadle, S. E.; Hedman, B.; Hodgson, K. O.; Solomon, E. I. S K-edge X-ray Absorption Studies of Tetranuclear Iron-Sulfur Clusters: $\mu$-Sulfide Bonding and Its Contribution to Electron Delocalization. J. Am. Chem. Soc. 2001, 123 (3), 442-454.

(48) Ha, Y.; Arnold, A. R.; Nuñez, N. N.; Bartels, P. L.; Zhou, A.; David, S. S.; Barton, J. K.; Hedman, B.; Hodgson, K. O.; Solomon, E. I. Sulfur K-Edge XAS Studies of the Effect of DNA Binding on the [Fe4S4] Site in EndoIII and MutY. J. Am. Chem. Soc. 2017, 139 (33), 11434-11442.

(49) Sun, N.; Dey, A.; Xiao, Z.; Wedd, A. G.; Hodgson, K. O.; Hedman, B.; Solomon, E. I. Solvation Effects on S K-Edge XAS Spectra of Fe-S Proteins: Normal and Inverse Effects on WT and Mutant Rubredoxin. J. Am. Chem. Soc. 2010, 132 (36), 12639-12647.

(50) Bjornsson, R.; Delgado-Jaime, M. U.; Lima, F. A.; Sippel, D.; Schlesier, J.; Weyhermüller, T.; Einsle, O.; Neese, F.; DeBeer, S. Molybdenum L-Edge XAS Spectra of MoFe Nitrogenase. Z. Anorg. Allg. Chem. 2015, 641 (1), 65-71.

(51) Hedman, B.; Frank, P.; Gheller, S. F.; Roe, A. L.; Newton, W. E.; Hodgson, K. O. New structural insights into the iron-molybdenum cofactor from Azotobacter vinelandii nitrogenase through sulfur $\mathrm{K}$ and molybdenum L x-ray absorption edge studies. J. Am. Chem. Soc. 1988, 110 (12), 3798-3805.

(52) Kvashnina, K. O.; Butorin, S. M.; Cui, D.; Vegelius, J.; Puranen, A.; Gens, R.; Glatzel, P. Electron transfer during selenium reduction by iron surfaces in aqueous solution: High resolution X-ray absorption study. Journal of Physics: Conference Series 2009, 190 (1), No. 012191.

(53) Krause, M. O.; Oliver, J. H. Natural widths of atomic K and L levels, K $\alpha$ X-ray lines and several KLL Auger lines. J. Phys. Chem. Ref. Data 1979, 8 (2), 329-338.

(54) Pickering, I. J.; George, G. N.; Van Fleet-Stalder, V.; Chasteen, T. G.; Prince, R. C. X-ray absorption spectroscopy of seleniumcontaining amino acids. JBIC, J. Biol. Inorg. Chem. 1999, 4 (6), 791794.

(55) Castillo, R. G.; Banerjee, R.; Allpress, C. J.; Rohde, G. T.; Bill, E.; Que, L.; Lipscomb, J. D.; DeBeer, S. High-Energy-Resolution Fluorescence-Detected X-ray Absorption of the Q Intermediate of Soluble Methane Monooxygenase. J. Am. Chem. Soc. 2017, 139 (49), 18024-18033.

(56) Hämäläinen, K.; Siddons, D. P.; Hastings, J. B.; Berman, L. E. Elimination of the inner-shell lifetime broadening in $\mathrm{x}$-ray-absorption spectroscopy. Phys. Rev. Lett. 1991, 67 (20), 2850-2853.

(57) Kowalska, J. K.; Lima, F. A.; Pollock, C. J.; Rees, J. A.; DeBeer, S. A Practical Guide to High-resolution X-ray Spectroscopic Measurements and their Applications in Bioinorganic Chemistry. Isr. J. Chem. 2016, 56 (9-10), 803-815. 
(58) Gaillard, J.; Moulis, J. M.; Auric, P.; Meyer, J. High-multiplicity spin states of $2[4 \mathrm{Fe}-4 \mathrm{Se}]+$ clostridial ferredoxins. Biochemistry 1986, 25 (2), 464-468.

(59) Carney, M. J.; Papaefthymiou, G. C.; Spartalian, K.; Frankel, R. B.; Holm, R. H. Ground spin state variability in [Fe4S4(SR)4]3-. Synthetic analogs of the reduced clusters in ferredoxins and other iron-sulfur proteins: cases of extreme sensitivity of electronic state and structure to extrinsic factors. J. Am. Chem. Soc. 1988, 110 (18), 60846095.

(60) Davis, L. C.; Henzl, M. T.; Burris, R. H.; Orme-Johnson, W. H. Iron-sulfur clusters in the molybdenum-iron protein component of nitrogenase. Electron paramagnetic resonance of the carbon monoxide inhibited state. Biochemistry 1979, 18 (22), 4860-4869.

(61) Fohlmeister, L.; Vignesh, K. R.; Winter, F.; Moubaraki, B.; Rajaraman, G.; Pottgen, R.; Murray, K. S.; Jones, C. Neutral diiron(iii) complexes with $\mathrm{Fe} 2([$ small $\mathrm{mu}]-\mathrm{E}) 2(\mathrm{E}=\mathrm{O}, \mathrm{S}, \mathrm{Se})$ core structures: reactivity of an iron(i) dimer towards chalcogens. Dalton Transactions 2015, 44 (4), 1700-1708.

(62) Panda, C.; Menezes, P. W.; Walter, C.; Yao, S.; Miehlich, M. E.; Gutkin, V.; Meyer, K.; Driess, M. From a Molecular 2Fe-2Se Precursor to a Highly Efficient Iron Diselenide Electrocatalyst for Overall Water Splitting. Angew. Chem., Int. Ed. 2017, 56 (35), 1050610510.

(63) Yu, S. B.; Papaefthymiou, G. C.; Holm, R. H. Comprehensive iron-selenium-thiolate cluster chemistry. Inorg. Chem. 1991, 30 (18), 3476-3485.

(64) Anxolabéhère-Mallart, E.; Glaser, T.; Frank, P.; Aliverti, A.; Zanetti, G.; Hedman, B.; Hodgson, K. O.; Solomon, E. I. Sulfur KEdge X-ray Absorption Spectroscopy of $2 \mathrm{Fe}-2 \mathrm{~S}$ Ferredoxin: Covalency of the Oxidized and Reduced 2Fe Forms and Comparison to Model Complexes. J. Am. Chem. Soc. 2001, 123 (23), 5444-5452. (65) Yoshioka, S.; Tosha, T.; Takahashi, S.; Ishimori, K.; Hori, H.; Morishima, I. Roles of the Proximal Hydrogen Bonding Network in Cytochrome P450cam-Catalyzed Oxygenation. J. Am. Chem. Soc. 2002, 124 (49), 14571-14579.

(66) Dey, A.; Okamura, T.-a.; Ueyama, N.; Hedman, B.; Hodgson, K. O.; Solomon, E. I. Sulfur K-Edge XAS and DFT Calculations on P450 Model Complexes: Effects of Hydrogen Bonding on Electronic Structure and Redox Potentials. J. Am. Chem. Soc. 2005, 127 (34), 12046-12053.

(67) Ueno, T.; Nishikawa, N.; Moriyama, S.; Adachi, S.; Lee, K.; Okamura, T.-a.; Ueyama, N.; Nakamura, A. Role of the Invariant Peptide Fragment Forming NH..S Hydrogen Bonds in the Active Site of Cytochrome P-450 and Chloroperoxidase: Synthesis and Properties of Cys-Containing Peptide Fe(III) and Ga(III) (Octaethylporphinato) Complexes as Models. Inorg. Chem. 1999, 38 (6), $1199-1210$.

(68) Ueyama, N.; Terakawa, T.; Nakata, M.; Nakamura, A. Positive shift of redox potential of [Fe4S4(Z-cys-Gly-Ala-OMe)4]2- in dichloromethane. J. Am. Chem. Soc. 1983, 105 (24), 7098-7102.

(69) Lowe, D. J.; Fisher, K.; Thorneley, R. N. F. Klebsiella pneumoniae nitrogenase. Mechanism of acetylene reduction and its inhibition by carbon monoxide. Biochem. J. 1990, 272 (3), 621.

(70) Cameron, L. M.; Hales, B. J. Investigation of CO Binding and Release from Mo-Nitrogenase during Catalytic Turnover. Biochemistry 1998, 37 (26), 9449-9456.

(71) Yan, L.; Dapper, C. H.; George, S. J.; Wang, H.; Mitra, D.; Dong, W.; Newton, W. E.; Cramer, S. P. Photolysis of Hi-CO Nitrogenase - Observation of a Plethora of Distinct CO Species Using Infrared Spectroscopy. Eur. J. Inorg. Chem. 2011, 2011 (13), 2064-2074.

(72) Yan, L.; Pelmenschikov, V.; Dapper, C. H.; Scott, A. D.; Newton, W. E.; Cramer, S. P. IR-Monitored Photolysis of COInhibited Nitrogenase: A Major EPR-Silent Species with Coupled Terminal CO Ligands. Chem. - Eur. J. 2012, 18 (51), 16349-16357.

(73) Arnett, C. H.; Chalkley, M. J.; Agapie, T. A Thermodynamic Model for Redox-Dependent Binding of Carbon Monoxide at SiteDifferentiated, High Spin Iron Clusters. J. Am. Chem. Soc. 2018, 140 (16), 5569-5578. 